\title{
Two Decades of Spatiotemporal Variations in Subduction Zone Coupling Offshore Japan
}

John P. Loveless

Smith College, jloveles@smith.edu

Brendan J. Meade

Harvard University

Follow this and additional works at: https://scholarworks.smith.edu/geo_facpubs

Part of the Geology Commons

\section{Recommended Citation}

Loveless, John P. and Meade, Brendan J., "Two Decades of Spatiotemporal Variations in Subduction Zone Coupling Offshore Japan" (2016). Geosciences: Faculty Publications, Smith College, Northampton, MA.

https://scholarworks.smith.edu/geo_facpubs/10 


\title{
Two decades of spatiotemporal variations in subduction zone coupling offshore Japan
}

\author{
John P. Loveless ${ }^{a,}$ * and Brendan J. Meade ${ }^{b}$ \\ ${ }^{a}$ Department of Geosciences, Smith College, 44 College Lane, Northampton, MA 01063, USA \\ (jloveless@smith.edu) \\ ${ }^{\mathrm{b}}$ Department of Earth and Planetary Sciences, Harvard University, 20 Oxford Street, Cambridge, MA \\ 02138,USA (meade@fas.harvard.edu) \\ * Corresponding author: Tel.: +1 4135852657
}




\section{Abstract}

2 Spatial patterns of interplate coupling on global subduction zones can be used to

3 guide seismic hazard assessment, but estimates of coupling are often constrained using a

4 limited temporal range of geodetic data. Here we analyze $\sim 19$ years of geodetic

5 observations from the GEONET network to assess time-dependent variations in the

6 spatial distribution of coupling on the subduction zones offshore Japan. We divide the

7 position time series into five, $\sim 3.75$-year epochs each decomposed into best-fit velocity,

8 annual periodic signals, coseismic offsets, and postseismic effects following five major

9 earthquakes. Nominally interseismic velocities are interpreted in terms of a combination

10 tectonic block motions and earthquake cycle activity. The duration of the inferred

11 postseismic activity covaries with the linear velocity. To address this trade-off, we

12 assume that the nominally interseismic velocity at each station varies minimally from

13 epoch to epoch. This approach is distinct from prior time-series analysis across the

14 earthquake cycle in that position data are not detrended using preseismic velocity, which

15 inherently assumes that interseismic processes are spatially stable through time, but rather

16 the best-fit velocity at each station may vary between epochs. These velocities reveal

17 significant consistency since 1996 in the spatial distribution of coupling on the Nankai

18 subduction zone, with variation limited primarily to the Tokai and Bungo Channel

19 regions, where long-term slow slip events have occurred, and persistently coupled

20 regions coincident with areas that slipped during historic great earthquakes. On the

21 Sagami subduction zone south of Tokyo, we also estimate relatively stable coupling

22 through time. On the Japan-Kuril Trench, we image significant coupling variations owing 
23 to effects of the $1994 \mathrm{M}_{\mathrm{W}}=7.7$ Sanriku-oki, $2003 \mathrm{M}_{\mathrm{W}}=8.2$ Tokachi-oki, and 2011

$24 \quad \mathrm{M}_{\mathrm{W}}=9.0$ Tohoku-oki earthquakes. In particular, strong coupling becomes more spatially

25 extensive following the 1994 event until 2011, coseismic-sense slip precedes the Tohoku-

26 oki event, and coupling offshore northern Honshu is reduced after the 2011 earthquake.

27 Despite the occurrence of the 2003 Tokachi-oki earthquake, persistent coupling offshore

28 Hokkaido suggests ongoing seismic hazard, possibly similar to past $\mathrm{M}_{\mathrm{W}} \sim 9$-class

29 earthquakes interpreted from coastal paleoseismic records. This time-dependent analysis

30 of interseismic deformation illuminates rich diversity in the distribution of subduction

31 zone coupling, including spatiotemporal stability in coupling, effective reduction in

32 strongly coupled regions due to aseismic thrust-sense slip events, and broad changes in

33 the distribution of coupling following major earthquakes.

34 Keywords: subduction zone; Japan; coupling; earthquake cycle 


\section{1. Introduction}

36 Over the past two decades, the proliferation of high-precision geodetic observations

37 and occurrence of large earthquakes have enabled imaging of processes spanning the

38 earthquake cycle, including interseismic strain accumulation, abrupt coseismic strain

39 release, and transient behavior such as postseismic afterslip, postseismic viscoelastic

40 relaxation of the lower crust and/or upper mantle, and aseismic slip during the nominally

41 interseismic period. Geodetic displacement time series have led to the discovery of

42 spatial variations in interseismic coupling (McCaffrey et al., 2000; Nishimura et al.,

43 2004), constraints on the viscosity of Earth's lower crust (Hearn et al., 2009; Pollitz et al.,

44 2000), and the occurrence of aseismic slow slip events (Dragert et al., 2001; Hirose et al., 45 1999).

46 The GEONET GNSS array has measured surface displacement across the Japanese

47 Islands at $>800$ stations since 1996. These crustal deformation observations have been

48 interpreted as reflecting earthquake cycle processes on the network of crustal faults

49 throughout Japan and the three subduction interfaces offshore (Nankai Trough, Sagami

50 Trough, Japan-Kuril Trench; Figure 1a) (Hashimoto et al., 2000; Loveless and Meade,

51 2010; Nishimura et al., 2004). Previous studies have focused on either spatiotemporal

52 evolution of subduction zone coupling on an isolated subduction zone section

53 (Hashimoto et al., 2009; Liu et al., 2010; Mavrommatis et al., 2014; Nishimura et al.,

54 2004), or nationwide tectonics using a limited time period of GEONET observations

55 (Hashimoto et al., 2000; Loveless and Meade, 2010).

56 Here we analyze GEONET data in five, 3.75 -year epochs spanning April 1996

57 through December 2014. For each epoch, we fit each station time series with a 
58 combination of linear, periodic, step, and exponential functions, which we interpret to

59 represent nominally interseismic deformation related to earthquake cycle processes on the

60 subduction zones and crustal faults, seasonal effects, offsets due to earthquakes and

61 equipment maintenance, and postseismic deformation following large earthquakes,

62 respectively. We use the linear velocity fields as constraints on quasi-static elastic block

63 models, which provide a means for interpreting geodetic observations resulting from the

64 combined effects of tectonic block rotations, earthquake cycle processes (Meade and

65 Loveless, 2009), and volume changes of magma bodies. We use these models to image

66 patterns of subduction zone coupling in each of the five epochs, identifying persistently

67 coupled regions, effects of large earthquakes on subduction zone coupling, and the

68 occurrence of aseismic slip events.

\section{2. Methods}

\subsection{Decomposition of displacement time series}

71 We analyze F3 daily coordinates from the Geospatial Information Authority of Japan

72 during five time periods: April 1, 1996-December 31, 1999 (1996.25-2000.00; 3.75 year

73 duration); January 1, 2000-September 24, 2003 (before the $\mathrm{M}_{\mathrm{W}}=8.2$ Tokachi-oki

74 earthquake offshore Hokkaido, 2000.00-2003.73; 3.73 years); September 25, 2003-June

7530,2007 (2003.73-2007.50; 3.77 years); July 1, 2007-March 10, 2011 (before the

$76 \mathrm{M}_{\mathrm{W}}=9.0$ Tohoku-oki earthquake offshore northern Honshu, 2007.50-2011.19; 3.69

77 years); and March 11, 2011-December 31, 2014 (2011.19-2015.00; 3.81 years). For the

78 entire time series, we fit individual station position time series, $\mathbf{x}(t)$, where the vector $\mathbf{x}$ 
79 represents the position in the east or north direction, using piecewise linear, periodic, step

80 and exponential functions:

$$
\mathbf{x}(t)=\sum_{i=1}^{N_{\text {epoch }}} \mathbf{A}_{i} * \mathrm{I}(t)\left(t-t_{i}\right)+\sum_{j=1}^{2}\left(\mathbf{B}_{j} \sin \frac{2 \pi j t}{T_{\mathrm{yr}}}+\mathbf{C}_{j} \cos \frac{2 \pi j t}{T_{\mathrm{yr}}}\right)
$$

$$
+\sum_{k=1}^{N_{\text {step }}} \mathbf{D}_{k} \mathrm{H}\left(t-t_{k}\right)
$$

$$
+\sum_{m=1}^{2} \sum_{n=1}^{N_{\mathrm{eq}}} \mathbf{E}_{(2(n-1)+m)} \mathrm{H}\left(t-t_{n}\right)\left(1-e^{\left(t_{n}-t\right) / \tau_{m}}\right)
$$

84 where

$$
\mathrm{I}(t)=\left\{\begin{array}{l}
1 \quad \text { for } t_{i} \leq t<t_{i+1} \\
0 \quad \text { for } t<t_{i} \text { and } t \geq t_{i+1}
\end{array}\right.
$$

86 and

$$
\tau_{m}=\frac{P_{m} * T_{\mathrm{yr}}}{-\ln (0.05)}
$$

88 A is the linear slope during each epoch, which we take to reflect the nominally

89 interseismic velocity; I is an index function defined such that $\mathrm{I}=1$ for time values within

90 the epoch and zero for times before and after; $\mathbf{B}$ and $\mathbf{C}$ are amplitudes of annual and

91 semiannual periodic terms; D gives the amplitude of steps in the time series

92 corresponding to earthquakes, equipment (antenna) changes, and ordinate-intercepts

93 accompanying linear terms; $\mathrm{H}$ is the Heaviside step function; and $\mathbf{E}$ is the amplitude of

94 postseismic deformation following specified earthquakes. The decay constants, $\tau_{m}$,

95 correspond to durations $P_{m}$ (in years) following an earthquake when the exponential

96 function reaches $95 \%$ peak asymptotic amplitude $\mathbf{E}$. In all terms, $t$ is the time in days 
97 since the beginning of the analysis time period, $T_{\mathrm{yr}}$ is the duration of a year in days, and

98 subscripted $t$ values in linear, step, and exponential functions refer to dates of epoch

99 initiation, offsets, and major earthquakes, respectively. We consider 23 values of $\tau_{2}$,

100 corresponding to durations of exponential signal ranging from 6 months to 10 years in 6

101 month intervals, plus 25, 50, and 100 years. In all trials, we also fit a function described

102 by $\tau_{1}$ with a 3 -month decay, capturing rapid evolution of surface deformation near the

103 earthquake source. However, in cases where the sign of $\mathbf{E}$ corresponding to a $\tau_{1}$ term

104 differs from that of the associated $\tau_{2}$ term, we eliminate the $\tau_{1}$ term and estimate $\mathbf{E}$ for

105 the longer duration only.

106 For all epochs, we evaluate the quality of fit to the data as the mean magnitude of

107 daily position residuals between observations and total fit from Equation 1. This

108 approach differs from formal calculation of uncertainties from the model covariance

109 matrix, which is not straightforward given the absence of reported uncertainties on F3

110 position data. The mean residuals serve as relative weights on linear velocities in our

111 inversion for earthquake cycle processes. Epoch-averaged mean residual positions range

112 from $1.57 \mathrm{~mm}$ (north component of Epoch 4) to $5.55 \mathrm{~mm}$ (east component of Epoch 1).

113 We estimate coseismic jumps for up to 200 earthquakes (1996-2014, $\mathrm{M}_{\mathrm{W}} \geq 6$, depth $\leq$

$11450 \mathrm{~km}$ as given in the Global CMT catalog) and consider postseismic deformation

115 following the $2003 \mathrm{M}_{\mathrm{W}}=8.2$ Tokachi-oki, $2004 \mathrm{M}_{\mathrm{W}}=7.2-7.3$ off-Kii Peninsula, 2005

$116 \mathrm{M}_{\mathrm{W}}=7.2$ Miyagi, $2006 \mathrm{M}_{\mathrm{W}}=8.3$ Kuril Islands, $2008 \mathrm{M}_{\mathrm{W}}=6.9$ Iwate-Miyagi Nairiku, 2010

$117 \mathrm{M}_{\mathrm{W}}=6.5$ Fukushima, and $2011 \mathrm{M}_{\mathrm{W}}=9.0$ Tohoku-oki events. We follow an approach

118 similar to that of Ikuta et al. (2012), estimating coseismic steps and exponential

119 postseismic terms at stations within $10^{0.36 \mathrm{M}_{\mathrm{W}}-0.15} \mathrm{~km}$ of the earthquake epicenter. For 
120 the Tokachi-oki and Tohoku-oki earthquakes, we estimate postseismic deformation at all

121 stations. The scaling of the magnitude-dependent distances was evaluated by eye,

122 assessing whether or not displacement time series exhibited clear coseismic offsets and

123 therefore likely include postseismic deformation.

\section{$124 \quad$ 2.2. Interpretation of time series terms}

125 The exponential term in Equation 1a corresponding to values of assumed $\tau_{2}$

126 negatively covaries with velocity $\mathbf{A}$, with the longest decay durations producing

127 exponential signals inversely proportional to the estimated linear term (Figure $\mathbf{2}, \mathbf{3}$ ). In

128 some cases of long $\tau_{2}$, the exponential contribution to the functional fit to the position

129 time series shows a different sign than the linear term. For large Pacific Coast

130 earthquakes, which produce eastward (trenchward) co- and postseismic displacements,

131 such fitting of the position data could be interpreted as large magnitude viscoelastic

132 relaxation and/or afterslip, producing eastward movement, slowed by westward motion

133 from resumed interseismic coupling, yielding a net slow eastward signal (e.g., the 10-year

134 fit in Figure 2).

135 Covariance between exponential and linear terms for epochs following large

136 earthquakes (Figure 3) leads to, particularly in the case of long assumed decay times,

137 degeneracy in uniquely mapping time series analysis terms to either postseismic

138 viscoelastic relaxation or megathrust slip behavior. In this analysis, we make the end-

139 member assumption that exponential terms represent time-decaying postseismic

140 deformation, comprising combined megathrust afterslip and viscoelastic relaxation, with

141 decay times specified by $\tau_{m}$ values. The linear term is interpreted to represent convolved

142 contributions from coupling on megathrusts, rotation of crustal blocks, and elastic strain 
143 accumulation due to locking on block boundaries. In other words, estimated linear terms

144 for each epoch represent the velocity field we use to constrain quasi-static elastic block

145 models of interseismic deformation. This velocity decomposition may map some

146 viscoelastic relaxation onto megathrust and microplate slip and/or slip deficit. Though

147 afterslip and resumption of interseismic coupling are spatiotemporally varying processes,

148 we here consider estimated deformation patterns as reflecting time-averaged earthquake

149 cycle behavior throughout each epoch.

$150 \quad$ 2.3. Constructing minimally variable velocity fields

151 As a basis for evaluating temporal stability of spatial patterns of subduction zone

152 coupling, we determine interseismic velocities that vary minimally from epoch to epoch.

153 Due to infrequent macroscale seismicity from 1996-2000 (Loveless and Meade, 2010;

154 Sagiya et al., 2000), we use the Epoch 1 velocity field (Figure 1) as a reference epoch

155 against which subsequent epoch velocities are compared. To construct what we term

156 minimally variable velocity fields (MVVF), we choose, at each station $s$, during each

157 epoch $\varepsilon$, the $\tau_{2}$ value that yields a velocity vector, $\mathbf{A}$, most similar in magnitude to that

158 estimated using a 1-year decay duration during Epoch 1,

$$
\hat{\tau}_{2}(s, \varepsilon)=\arg \min _{\tau_{2}}\left(\left\|\mathbf{A}\left(s, \varepsilon, \tau_{2}\right)-\mathbf{A}(s, 1,1)\right\|\right) .
$$

160 In other words, we select the duration of postseismic deformation at each station

161 assuming that subduction zone coupling varies as little as possible through time (Figure

$1624)$.

163 Construction of the MVVF is consistent with the formal assumption of prior geodetic

164 imaging studies spanning multiple earthquake cycles (Ergintav et al., 2009) in that the 
165 linear contribution to the time series fit, interpreted to represent interseismic strain

166 accumulation, is similar through time at each station. However, the MVVF is distinct in

167 that a station's interseismic velocity can and does vary through time (Figure 4, Figure 5),

168 as the station velocity is not formally constrained to remain temporally constant but

169 rather is as similar as possible to the Epoch 1 velocity. This assumption may

170 underestimate true variation in interseismic coupling and overestimate postseismic

171 deformation, points we return to in Sections 4.1 and 4.2.

$172 \quad$ 2.4. Block modeling

173 We filter from each epoch velocity field poorly constrained and spatially inconsistent

174 stations, removing those with mean residual positions $\geq 12.5 \mathrm{~mm}$ and those that differ

175 from the average velocity at neighboring stations within $20 \mathrm{~km}$ by $\geq 5 \mathrm{~mm} / \mathrm{yr}$. We then

176 place each velocity field into the reference frame of Apel et al. (2006), using a 6-

177 parameter (rotation plus translation) transformation to align velocities at stations

178 collocated in GEONET fields and the Apel et al. (2006) field. The transformation

179 parameters are estimated by linear least-squares fitting that aligns the Epoch 1 velocity

180 field with that of Apel et al. (2006). To facilitate comparison of model results, we retain

181 only those stations that are present in all epochs.

182 Using a three-dimensional elastic block modeling framework (Meade and Loveless,

183 2009), we simultaneously estimate Euler poles for 20 tectonic blocks; spatially variable

184 slip deficit rates on the Japan-Kuril Trench, Nankai Trough, and Sagami Trough

185 subduction zones; and magma chamber volume change rates at 3 locations. The block

186 geometry is as given in Loveless and Meade (2010), based on plate boundary models

187 (Bird, 2003), the digital active fault map of Japan (Nakata and Imaizumi, 2002), and 
188 previous crustal deformation studies (Hashimoto and Jackson, 1993; Nakamura, 2004;

189 Nishimura and Hashimoto, 2006; Nishimura et al., 2007). The subduction zone interfaces

190 are tessellated using triangular dislocation elements (TDEs), with the interface geometry

191 defined by various geophysical studies (Furuse and Kono, 2003; Hirose et al., 2008; Toda

192 et al., 2008). We use each realization of the velocity field, described above, along with $a$

193 priori assumptions that the subduction zone slip deficit rate distribution be a) spatially

194 smooth across the plate interface, with the strength of this constraint set so that the

195 maximum magnitude of slip deficit is similar to the relative plate motion projected onto

196 the subduction zone elements (Loveless and Meade, 2010); b) zero on TDEs at the deep

197 extent of each subduction zone, representing a transition to fault creep behavior; and c)

198 zero on TDEs lining the subduction trenches. We also show results for models in which

199 this latter constraint is relaxed, reflecting poor resolution of coupling patterns near the

200 subduction trench (Loveless and Meade, 2011) and the possibility that interseismic

201 coupling may extend to the trench (Gagnon et al., 2005). We also estimate volume

202 change rates by representing magma bodies as buried spherical sources, relating radial

203 surface velocities around each body due to unit volume change (Mogi, 1958).

\section{3. Results}

\subsection{Estimated duration of postseismic effects}

As an illustration of MVVF construction, we show stations symbolized by the

207 postseismic decay duration that yields temporal consistency in linear velocity $\mathbf{A}$ for

208 Epochs 3 and 5, corresponding to the time periods following the Tokachi-oki and

209 Tohoku-oki earthquakes, respectively (Figure 4). In general, longer decay durations are 
210 required at stations around the earthquake source regions. Notable exceptions include

211 long (7-10-year) decay times around Tokai during Epoch 3, which may reflect a long-

212 term slow slip event from 2000-2005 beneath Tokai (Miyazaki et al., 2006; Ochi and

213 Kato, 2013), and longer decay times estimated on the west coast of northern Honshu (10

214 years) than on the east coast (8 years) following the Tohoku-oki earthquake. The chosen

215 decay constants for Epochs 3 and 5 can be interpreted as the duration of postseismic

216 deformation following the Tokachi-oki and Tohoku-oki earthquakes, respectively, under

217 the MVVF assumption that the spatial pattern of interseismic deformation changes little

218 through time. Short-wavelength fluctuations in postseismic duration may reflect localized

219 temporal variation in earthquake cycle process distinct from great earthquakes, including

220 smaller subduction and crustal earthquakes, transient deformation, and volcano-related

221 deformation (Table S6).

\section{$222 \quad 3.2$. Interseismic velocities through time}

223 We examine changes in MVVF vectors through time relative to Epoch 1 (Figure 1a).

224 In the following discussion, references to regions (Figure $1 \mathrm{~b}$ ) are, in general, to their

225 Pacific coastal sections, and references to speed and direction are relative to those of

226 Epoch 1, with numerical values indicating maximum speed difference.

227 During Epoch 2 (Figure 5a), the most discernable velocity change is slower (by up to

$228 \sim 18 \mathrm{~mm} / \mathrm{yr}$ ), more trenchward (southeast) motion in Tokai and Kanto. Additional

229 velocity changes include slower $(7 \mathrm{~mm} / \mathrm{yr})$, more landward (northwest) motion of the

230 majority of Kyushu; faster $(6 \mathrm{~mm} / \mathrm{yr})$ and more eastward motion in southern Hokuriku;

231 slightly slower $(5 \mathrm{~mm} / \mathrm{yr})$, more trenchward motion in southern Tohoku $\left(38^{\circ} \mathrm{N}\right)$; and

232 faster $(5 \mathrm{~mm} / \mathrm{yr})$, more landward motion in northern Tohoku. 
233 During Epoch 3 (Figure 5b), velocity change in Hokkaido, with the exception of a

234 few scattered stations, is small, suggesting little change in interseismic deformation

235 following the 2003 Tokachi-oki earthquake. Northern Tohoku again shows faster (8

$236 \mathrm{~mm} / \mathrm{yr}$ ), more landward velocities, while central Tohoku shows continued slower (8

$237 \mathrm{~mm} / \mathrm{yr}$ ), trenchward motion. The Kanto-Tokai region shows little velocity change; a

238 cluster of slower $(8 \mathrm{~mm} / \mathrm{yr})$, southeast vectors appears on the Izu Peninsula, which may

239 reflect offshore volcanic deformation. Hokuriku and Kyushu show velocity changes

240 similar to those of Epoch 2, indicating little change in motion between Epochs 2 and 3.

241 Comparing Epoch 4 (Figure 5c) to Epoch 1, slowed (10 mm/yr), northwestward

242 velocities again characterize much of Kyushu, indicating consistency in velocity since

243 2000.0. This pattern is also present in Chugoku, with velocities decreased by up to 6

$244 \mathrm{~mm} / \mathrm{yr}$. Velocity changes in Tohoku (faster $(9 \mathrm{~mm} / \mathrm{yr}$ ) and more landward in the north,

245 slower (12 mm/yr) and more trenchward in the south) are accentuated since Epoch 3,

246 showing a pattern of counterclockwise rotation. Velocities in southwest Hokkaido are

247 slower (4 mm/yr) and more northeasterly, but stations in the northeast move faster (5

$248 \mathrm{~mm} / \mathrm{yr}$ ) and more landward.

249 Velocity changes in Epoch 5 (Figure 5d) are randomly oriented across much of

250 northern Honshu, near the source region of the 2011 Tohoku-oki earthquake, with more

251 spatially coherent patterns in other regions. In southern Hokkaido, velocities are slower

$252(10 \mathrm{~mm} / \mathrm{yr})$ and more southeasterly than in Epoch 1. In the coastal Tokai-southern Kanto

253 region, velocities are trenchward and slowed (20 mm/yr) compared to those of Epoch 1,

254 showing a pattern similar to that of Epoch 2. To the northwest, in northern Chubu and

255 western Hokuriku, stations show similar directional change but move faster $(26 \mathrm{~mm} / \mathrm{yr})$ 
256 than during Epoch 1, suggesting shortening in Chubu. The spatial coherence and large

257 magnitude of these velocity changes suggest that far-field postseismic deformation may

258 be inadequately modeled, and changes in interseismic coupling inferred from these

259 velocities may in fact convolve post- and interseismic processes. In western Kinki and

260 Chugoku, vectors are mostly faster $(13 \mathrm{~mm} / \mathrm{yr})$ and more eastward, reversing the pattern

261 of Epoch 4. Much of Kyushu shows little velocity change relative to Epoch 1, though

262 faster $(7 \mathrm{~mm} / \mathrm{yr})$, eastward vectors characterize the southern extreme.

\subsection{Spatiotemporal variation in subduction zone coupling}

264 Using MVVF velocity estimates for each epoch as constraints on block models, we

265 simultaneously estimate tectonic plate motions and spatially variable slip deficit rates on

266 subduction zone interfaces. These rates are converted to coupling coefficients by

267 normalizing the slip deficit rate by the relative block motion rate projected onto each

268 triangular element. We place no bounds on the estimated slip deficit rate, instead

269 choosing smoothing values that result in rates on no more than $10 \%$ of elements of each

270 subduction zone exceeding the plate convergence rate. Given the spatial complexity in

271 estimated coupling distributions, we focus our discussion on regions we estimate to be

272 strongly coupled (slip deficit rate $\geq 80 \%$ relative block motion rate, Figure 6) and regions

273 that experience thrust-sense slip (at $\geq 10 \%$ the block motion rate, Figure 7), which we

274 interpret as aseismic creep occurring during the nominally interseismic period. We

275 estimate uncertainties in coupling as the standard deviation about the mean from Monte

276 Carlo simulations, inverting 5000 realizations of the velocity field predicted by forward

277 modeling of the slip deficit distribution, perturbed by noise proportional to the station

278 uncertainties. The along-strike extent of strongly coupled regions is generally consistent 
279 between models in which slip deficit along the subduction trenches is constrained to be 280 zero, which we refer to as trench-creeping (TC) models (Figure 6), and those in which

281 this constraint is not applied (trench-unconstrained (TU) models). The near-trench

282 behavior of many subduction megathrusts is poorly constrained by land-based geodetic

283 data due to great ( $\geq 200 \mathrm{~km}$ ) distance between stations and the trench (Loveless and

284 Meade, 2011). Though coseismic slip during the Tokoku-oki earthquake reached the

285 trench, dynamic overshoot (Ide et al., 2011) is a hypothesis that may explain observed

286 shallow rupture, even in the absence of persistent shallow coupling. We present the TC

287 models, in which smoothing features from poorly resolved regions do not propagate

288 down-dip where resolution is greater, but we discuss comparisons with TU models and

289 show equivalent TU results in Figures S1-S3, corresponding to TC results in Figure 6-8.

290 We find $\geq 80 \%$ coupling during Epoch 1 offshore Hokkaido and central Tohoku

$291\left(38^{\circ} \mathrm{N}\right)$ on the Japan Trench; on the western Sagami Trough; and beneath eastern Tokai,

292 and in 2 regions on the Nankai Trough beneath Shikoku and the Kii Peninsula-Tokai

293 region (Figure 6a). During Epoch 2 (Figure 6b), coupling is similar to that of Epoch 1 in

294 both TC and TU models, though with southwest expansion of the Shikoku patch to

295 offshore central Kyushu, representing an area increase of nearly $50 \%$.

296 In Epoch 3 (Figure 6c), following the 2003 Tokachi-oki earthquake, coupling

297 migrates deeper than in prior epochs at the bend in the Japan-Kuril Trench at $42^{\circ} \mathrm{N}$, to

$298 \sim 60 \mathrm{~km}$ compared to $\sim 40 \mathrm{~km}$. Offshore eastern Hokkaido, the depth extent of coupling is

299 less than in prior epochs (reduced from $\sim 60 \mathrm{~km}$ to $\sim 40 \mathrm{~km}$ ), and instead we estimate a

300 region of deep, thrust-sense slip (Figure 7c). Offshore Tohoku, we estimate a deeper

301 region of strong coupling. The TC model also extends to the north by about $1^{\circ}$, 
302 representing an increase in area of strong coupling of $25 \%$, and the TU model shifts

303 deeper than in Epoch 2, leaving the trench less coupled (Figure S1c). On the Sagami

304 Trough, the extent of strong coupling appears similar as during Epochs 1 and 2. On the

305 Nankai Trough, strong coupling appears similar to that of Epoch 2 but with an additional

306 patch of coupling near the northeast extent.

307 During Epoch 4 (Figure 6d), prior to the 2011 Tohoku-oki earthquake, the down-dip

308 extent of the Tohoku coupling patch is narrower (by about $30 \mathrm{~km}$ in the TC model) than

309 during prior epochs near its southern limit, and we estimate forward sense slip on the

310 deep interface from $35^{\circ}-37^{\circ} \mathrm{N}$. The Sagami Trough shows coupling similar to that of

311 Epochs 1 and 3. On the Nankai subduction zone, coupling near Tokai and the Kii

312 Peninsula is similar to Epoch 3 but the southwest coupling patch contracts to an area

313 similar to that during Epoch 1.

314 The spatial distribution of coupling on Nankai is consistent through Epoch 5, with a

315 southwestern patch intermediate in its southwest extent to that of Epochs 1 and 4, and

316 Epochs 2 and 3, and shallow coupling through the Tokai region to $137^{\circ} \mathrm{E}$ (Figure 6e). The

317 strongly coupled region on the Sagami Trough shows growth since prior epochs, about

$31840 \%$ larger than in Epoch 4. On the Japan Trench, we estimate strong coupling beneath

319 the coastline between $36-38^{\circ} \mathrm{N}$ and offshore $39^{\circ} \mathrm{N}$ in TC and TU models. Coupling

320 offshore Hokkaido is substantially reduced in southwest extent, with the patch

321 terminating around the southeast corner of the island; the overall area of this coupled

322 patch is about half that of Epoch 4. 


\subsection{Spatiotemporal variation in aseismic subduction zone slip}

324 Aseismic thrust-sense slip exceeding 10\% of local relative block motion rate is

325 concentrated mostly near the downdip extent of modeled subduction interfaces. As a

326 result, the distribution of thrust-sense slip is similar between TC and TU models.

327 During Epoch 1 (Figure 7a), thrust-sense slip is present on the Nankai subduction 328 interface beneath the southeast coast of Kyushu, and on the Japan Trench subduction

329 zone, we find a $\sim 200$-by-100 km patch of thrust slip near $40^{\circ} \mathrm{N}$, downdip from the source

330 area of the 1994 Sanriku-oki earthquake (Heki et al., 1997). During Epoch 2 (Figure 7b),

331 notable differences in thrust slip distribution are the presence of a patch around $137^{\circ} \mathrm{E}$

332 around Tokai, and $\sim 30 \%$ reduction in area of the Sanriku-oki patch.

333 During Epoch 3 (Figure 7c), after the 2003 Tokachi-oki earthquake, we image regions

334 of thrust slip beneath the northern half of the east coast of Hokkaido and beneath northern

335 Tohoku, similar to the Epoch 2 Sanriku-oki patch. The thrust-sense slip patch imaged

336 beneath Tokai in Epoch 2 does not appear during Epoch 3, though a small patch between

337 the Kii Peninsula and Shikoku does.

338 During Epoch 4, deep slip on the Japan Trench interface spans $35^{\circ}-37^{\circ} \mathrm{N}$, with an

339 insignificant patch near $39^{\circ} \mathrm{N}$. Beneath the Hokkaido coastline, slip occurs in a region

$340 \sim 30 \%$ smaller and shifted to the southwest $\sim 100 \mathrm{~km}$ relative to Epoch 2.

341 In Epoch 5 (Figure 7e) a broad, deep region of thrust-sense slip on the Japan Trench,

342 from $38^{\circ}-43^{\circ} \mathrm{N}$, spans the Japan-Kuril Trench bend off southern Hokkaido. A shallower

343 ( $\leq 40 \mathrm{~km}$ depth) region of aseismic slip also occurs at $36^{\circ} \mathrm{N}$. Thrust-sense slip occurs

344 across a broader depth range on the Nankai interface than during previous epochs. In

345 particular, we estimate slip beneath Tokai from $20-50 \mathrm{~km}$ depth. 


\section{4. DISCUSSION}

347 4.1. Implications of interseismic-postseismic covariance

348 A recent focus of research in earthquake science has been on using GPS to distinguish

349 the effects of postseismic afterslip and viscoelastic relaxation following major

350 earthquakes (Diao et al., 2013; Sun et al., 2014; Yamagiwa et al., 2015). Diao et al.

351 (2013), by comparing afterslip models with and without viscoelastic relaxation, suggest

352 that viscoelastic relaxation contributed nominally to the postseismic deformation within

353 the first 1.5 years following the Tohoku-oki earthquake but accounts for an increasing

354 proportion of deformation through time. Yamagiwa et al. (2015), using viscoelastic

355 modeling of offshore and onshore GPS displacements, suggest that trenchward

356 postseismic motion of GEONET stations represents primarily the effect of afterslip,

357 which persists for about 2.5 years following the Tohoku-oki earthquake. On the other

358 hand, Sun et al. (2014) interpret the combination of landward postseismic motion

359 observed at seafloor geodetic sites above the Tohoku-oki rupture area and the

360 trenchward-moving coastal sites as resulting primarily from viscoelastic relaxation.

361 While these analyses focus on short-term postseismic deformation, longer-term

362 studies must take into account the possibility that the impact of interseismic deformation

363 on geodetic position time series is not necessarily the same as prior to the earthquake. In

364 other words, detrending the entire time series using pre-seismic, nominally secular station

365 velocity (Ergintav et al., 2009) may not be appropriate, since that velocity arises from a

366 particular distribution of interseismic processes that may differ from the subsequent

367 interseismic period. If the possibility that fault coupling (Mavrommatis et al., 2014)

368 and/or tectonic plate motion (Heki and Mitsui, 2013) has changed is not considered in 
369 analysis of postseismic geodetic data, inference of, for example, the rheological structure

370 of the lower crust and upper mantle may be incorrect. The occurrence of afterslip itself

371 defines a temporary change in the distribution of coupling and may persist for the

372 duration of the epochs analyzed here. This afterslip may have longer-lived and/or farther-

373 reaching effects by changing the pattern of resumed coupling across the earthquake

374 source. Even under our assumption that the contribution to station motion from coupling

375 is as temporally stable as possible, the Tokachi-oki and Tohoku-oki earthquakes perturb

376 the distributions of strong coupling and thrust-sense slip. For example, a southwestward-

377 migrating patch of deep thrust slip during Epochs 3 and 4 beneath the Hokkaido coastline

378 (Figure 7c, d) locally reduces the down-dip extent of strong coupling (Figure 6c, d).

379 Covariance between signatures of resumed coupling and postseismic deformation

380 (Figure 2, 3) demonstrates the ambiguity in uniquely ascribing observed deformation to

381 particular underlying physical processes. Sun et al. (2014) note that the assumed

382 thickness of the subducting slab and viscosity of the mantle wedge between the

383 subducting and overriding plates influence the temporal evolution of postseismic

384 displacement in a manner similar to our assumed exponential decay times. In fitting

385 geodetic time series, we attribute the linear component within each epoch to represent

386 time-averaged tectonic and fault coupling processes, but we do not attribute the

387 exponentially decaying motion to physical parameters. Nonetheless, covariance between

388 contributions from interpreted fault coupling and postseismic deformation indicates that

389 interpretation of rheological parameters from the postseismic form would be non-unique

390 without independent constraints on the spatiotemporal distribution of coupling. 


\subsection{Effect of exponential decay constant on coupling estimate}

392 The results described above make the inherent assumption that the spatial distribution

393 of subduction zone coupling has varied as little as possible since Epoch 1, yet we do in

394 fact see notable changes. If, rather than assuming spatially and temporally variable

395 postseismic duration in estimating nominally interseismic velocity fields used to

396 constrain block models, we assume a single exponential decay constant since 1996, we

397 estimate differences in coupling patterns relative to MVVF results in Epochs 3-5

398 following the 2003 Tokachi-oki earthquake. Assuming a 3-year decay duration (Figure

399 8a) shows a region of strong coupling offshore Hokkaido during Epoch 3 that is narrower

400 down-dip than the corresponding MVVF patch (Figure 6c), representing postseismic

401 deformation convolved with interseismic coupling, and generally similar patterns of

402 coupling off Tohoku and on the Sagami and Nankai interfaces. Coupling during Epoch 4

403 (Figure 8a) shows reduced southwest extent of the Tohoku patch similar to the MVVF

404 model (Figure 6d). Coupling offshore Hokkaido is less than half the area of the MVVF

405 model, separated from a distinct coupling patch at $41^{\circ} \mathrm{N}$. On the Nankai Trough, the

406 southern coupling patch extends farther southwest than the MVVF patch. For Epoch 5,

407 the 3-year decay velocity field yields a region of strong coupling from $40^{\circ} \mathrm{N}$ to the

408 northeast extent of the modeled interface offshore Hokkaido (Figure 8a), nearly identical

409 in extent to the Epoch 4 coupling in the MVVF model (Figure 6d). Around Tohoku, we

410 estimate coupling entirely $<80 \%$, consistent with nominally interseismic velocities that in

411 fact contain substantial postseismic deformation owing to the short assumed decay

412 duration, which has been attributed by several studies to afterslip (Diao et al., 2013;

413 Evans and Meade, 2012; Ozawa et al., 2012; Yamagiwa et al., 2015). Epoch 5 coupling 
414 also differs substantially in the 3-year decay model compared to the MVVF model

415 (Figure 6e) on the Nankai Trough, with more spatially contiguous coupling spanning 416 nearly the entire modeled interface.

417 Assuming a 5-year decay duration (Figure 8b) results in strong Epoch 3 coupling that 418 is similar to that of the MVVF model, though coupling on the southern Japan Trench and

419 Nankai Trough is more spatially contiguous. During Epoch 4, coupling is more 420 segmented than the MVVF offshore Hokkaido and about $65 \%$ more extensive offshore

421 Tohoku. Coupling is similar to the MVVF model on the Nankai interface except near the 422 southwest extent of the southern patch. Epoch 5 shows similarities in coupling with the 3423 year decay model, with contiguous coupling across the Nankai Trough, no strong

424 coupling in the Tohoku-oki region, and coupling north of $40^{\circ}$ that is $70 \%$ larger than that 425 of the MVVF model, similar to the MVVF Epoch 4 distribution.

426 Using a 7-year decay time (Figure 8c) yields strong coupling during Epoch 3 similar

427 to the MVVF offshore Hokkaido and central Tohoku, but a patch is also estimated on the 428 deep part of the southern Japan Trench, as in the 5-year decay model. Coupling is

429 continuous across the entire Nankai interface. During Epoch 4, coupling in the 7-year 430 model is similar offshore Hokkaido and on the Sagami and Nankai Troughs, and double 431 in area off Tohoku compared to the MVVF model. In Epoch 5, the 7-year decay model is 432 segmented offshore Hokkaido and around the bend of the Japan-Kuril Trench, unlike in 433 the MVVF model (Figure 6e), and there is again little coupling in the Tohoku-oki region, 434 consistent with the MVVF-estimated postseismic durations $\geq 7$ years along the Tohoku 435 coast. 


\subsection{Coupling, aseismic slip, and seismic hazard implications}

437 The distribution of interseismic coupling imaged before the 2005 Nias (Sumatra),

4382007 Mentawai (Sumatra), 2011 Tohoku-oki, 2012 Nicoya (Costa Rica), and 2014

439 Iquique (Chile) subduction zone earthquakes shows positive spatial correlation with the

440 pattern of coseismic slip (Konca et al., 2008; Li et al., 2015; Loveless and Meade, 2011;

441 Protti et al., 2014). For the Tohoku-oki earthquake, a region coupled $\geq 30 \%$ of the long-

442 term convergence rate, estimated from the Epoch 1 velocity field, shows strong spatial

443 correlation with the region that slipped coseismically $\geq 4 \mathrm{~m}$ (Loveless and Meade, 2011).

444 Examining the temporal evolution of strong coupling offshore central Tohoku (Figure 6),

445 we see consistency in the location and more than doubling in area of the $\geq 80 \%$ coupled

446 patch from Epoch 1 to Epoch 2, and substantial expansion downdip and north along

447 strike in Epoch 3, with total patch area more than 3 times that of Epoch 1. In Epoch 4,

448 preceding the 2011 Tohoku-oki earthquake, the coupled region remains constant in area

449 but shows a northward shift. Concurrently, we estimate thrust-sense slip (Figure 7d) at

450 this downdip extent. This zone of forward-sense slip near the southern extent of the

451 Tohoku-oki rupture zone is consistent with the suggestion of Mavrommatis et al. (2014),

452 who modeled GEONET position time series considering an acceleration term in addition

453 to velocity and interpreted a decadal-scale aseismic transient in the region of our

454 estimated thrust slip during Epoch 4.

455 The Sanriku-oki region offshore northern Tohoku $\left(39^{\circ}-40^{\circ} \mathrm{N}\right)$ experienced a $\mathrm{M}_{\mathrm{W}}=7.7$

456 earthquake in 1994 with a period of afterslip lasting about 5 years (Heki et al., 1997;

457 Nishimura et al., 2004). The southward expansion of the off-Hokkaido coupled patch and 458 northward expansion of the off-Tohoku patch (in TC models) during Epochs 2-4 are 
consistent with resumed coupling in this region at depths of $20-40 \mathrm{~km}$ since the

460 beginning of Epoch 2 . At depths $\geq 60 \mathrm{~km}$ beneath the northern Tohoku coast, we image

461 thrust slip in all epochs, though the area and centroid of this thrust-slipping region vary

462 through time, such that, except for 4 triangular dislocation elements, no given portion of

463 the interface slips in all epochs (7f). The combination of deep, thrust-sense slip and

464 gradual resumption of coupling in the Sanriku-oki region since 1994 may have limited

465 the northern rupture extent of the 2011 Tohoku-oki earthquake, serving as a kinematic

466 barrier to rupture that had not accumulated sufficient moment to allow that event to

467 propagate north of $\sim 38^{\circ} \mathrm{N}$ (Loveless and Meade, 2015).

468 The northern concentration of strong coupling on the Japan-Kuril Trench subduction

469 zone, offshore Hokkaido, is consistently larger in area than that coinciding with the

$470 \quad \mathrm{M}_{\mathrm{w}}=9.0$ Tohoku-oki earthquake, particularly during Epochs 2-4. Great earthquakes

471 offshore Hokkaido have historically been substantially smaller than the Tohoku-oki event

472 - the 1952 and 2003 Tokachi-oki earthquakes were both $\mathrm{M}_{\mathrm{w}} \sim 8.2$ - but there is

473 precedent for $M_{w} \sim 9$-class earthquakes rupturing the interface beneath the entire Hokkaido

474 coastline with a $\sim 500$-year recurrence interval (Nanayama et al., 2003). Such events are

475 more consistent with the total area of $\geq 80 \%$ coupling in this region (Loveless and Meade,

476 2015), even given temporal variation in the distribution of coupling and thrust-sense slip

477 before and after the 2003 Tokachi-oki event (Figure 6, Figure 7).

478 Strong coupling on the western Sagami Trough, beneath the Boso Peninsula and

479 Tokyo Bay, has varied in area through time but remains consistent in location (Figure 6).

480 Episodic, aseismic slow slip events (SSEs) in May 1996, October 2002, and August 2007

481 on the eastern portion of the Sagami interface (Ozawa et al., 2003; Ozawa et al., 2007) 
may serve to modulate the nature of earthquakes across the entire subduction zone,

483 temporarily reducing the total area of strong coupling, which may thereby reduce overall

484 long-term seismic hazard. Our $\sim 3.75$-year epoch analysis does not resolve these $1-2$

485 week duration SSEs, in that the characteristic reversal in velocity direction is not imaged,

486 but estimated Epoch 2 velocities on the Boso Peninsula are reduced in magnitude and

487 directed more southeasterly relative to Epoch 1 (Figure 5a). The 1996 and 2007 SSEs

488 occur near the beginnings of Epochs 1 and 4, respectively, and the reversal in east and

489 north position is captured primarily by the ordinate-intercept term at epoch initiation. On

490 the other hand, the 2002 event occurs about three-quarters of the Epoch 2 duration, and

491 so it has greater impact than the other SSEs in reducing estimated northwest-directed

492 velocity relative to adjacent epochs. If strain accumulation due to coupling on the eastern

493 portion is partially relieved by periodic SSEs, the recurrence of large, 1703 Genroku-type

494 earthquakes rupturing much of the Sagami interface could be delayed, and between these

495 larger events, a greater number of 1923 Kanto earthquake-type events take place on the

496 western part of the interface.

497 On the Nankai subduction interface, we image spatiotemporal stability in

498 coupling since 1996. Strongly coupled patches offshore Shikoku and offshore the Kii

499 Peninsula are present in each epoch, with spatiotemporal fluctuation limited primarily to

500 the southwest extent of the southern patch near the Bungo Channel and the Tokai area,

501 both known localities of episodic SSEs (Miyazaki et al., 2006; Ozawa et al., 2013).

502 Bungo Channel SSEs in 1997, 2003, and 2010 have been interpreted from time series

503 analysis of local GEONET stations (Ozawa et al., 2013). The 2003 event occurred near

504 the transition from Epoch 2 to 3, and the lack of reduced coupling area we estimate 
505 during those epochs may suggest that velocity change due to the SSE may have been

506 absorbed into the postseismic signal estimated for the Tokachi-oki earthquake. However,

507 the 1997 and 2010 events occurred during Epochs 1 and 4, respectively, when the

508 southwest extent of the southern strong coupling patch was reduced (Figure 6a, d).

509 Importantly, even if the SSE duration is shorter than our $\sim 3.75$-year epochs, it may serve

510 to reduce the effective coupling below $80 \%$ during the epoch in which it occurs.

511 The coupled regions are spatially consistent with the estimated rupture areas of

512 Nankai/Tonankai and Tokai type earthquakes, respectively (Furumura et al., 2011;

513 Kodaira et al., 2006). Our persistent strong coupling region extends farther southwest

514 than several rupture models for the 1946 earthquake (Sagiya and Thatcher, 1999; Tanioka

515 and Satake, 2001) but is consistent with recent rupture scenarios for the 1707, whole-

516 margin Hoei-type earthquake based on tsunami records (Hyodo et al., 2014). The

517 separation between the Shikoku and Kii patches is spatially coincident with a subducted

518 seamount that has been seismically imaged and proposed as a potential barrier to

519 megathrust ruptures, including during the 1946 great Nankaido earthquake (Kodaira et

520 al., 2006). The temporal persistence of these segmented coupling zones is conceptually

521 consistent with long-term geologic control on earthquake cycle behavior by this

522 subducted seamount.

523 While physical properties of the subduction interfaces may exert influence on

524 seismogenic behavior, it is unclear which properties could vary on sub-decadal time

525 scales. We suggest that fluctuations in fluid pressure on the interface may be induced by

526 large coseismic stress changes such as those induced by the Tokachi-oki and Tohoku-oki

527 earthquakes and could explain some spatiotemporal variations in coupling. In particular, 
528 the dramatic contraction in area of the coupled patch offshore Hokkaido following the

529 Tohoku-oki earthquake may suggest that interface fluid pressure increased as a result of

530 coseismic stressing.

\section{5. Conclusions}

532 We analyzed GEONET position time series from 1996-2014 in five, $\sim 3.75$-year

533 epoch in order to assess the spatiotemporal evolution of interseismic coupling on the

534 Japanese subduction zones. Estimated transient postseismic deformation following major

535 earthquakes covaries with interseismic deformation, such that a change in the spatial

536 distribution of subduction zone coupling could be interpreted as an off-fault postseismic

537 effect such as viscoelastic relaxation. To address this covariance, we describe the

538 duration of postseismic deformation uniquely for each station and each epoch, assuming

539 that the interseismic contribution to station motion is as consistent as possible through

540 time. Even under this assumption that interseismic deformation patterns are temporally

541 stable, subduction zone coupling shows a remarkable diversity of behavior through time,

542 including:

543 a) A large region of strong coupling offshore Hokkaido that was reduced in area

544 by the 2003 Tokachi-oki earthquake and postseismic deformation as well as

545 by the more distal 2011 Tohoku-oki earthquake, but is consistent in spatial

546 extent with infrequent $\mathrm{M}_{\mathrm{W}} \sim 9$-class earthquakes inferred from the paleoseismic

$547 \quad$ record (Nanayama et al., 2003); 
b) Resumed coupling in the Sanriku-oki region following the 1994 earthquake, as shown by expansion of coupled patches offshore Tohoku (northward) and Hokkaido (southward);

c) Reduction in southern extent of strong coupling offshore Tohoku that is consistent with deep, aseismic thrust-sense slip preceding the 2011 Tohokuoki earthquake (Mavrommatis et al., 2014);

d) Stability of strong coupling on the Sagami Trough interface, restricted to a region west of the Boso Peninsula;

e) Stability of coupling across much of the Nankai Trough, with the exception of around Tokai, which has experienced several slow slip events, including a long-duration event from 2000-2005 (Miyazaki et al., 2006), and the southwest extent of the coupled patch offshore Shikoku around the Bungo Channel, which has also featured episodic slow slip (Ozawa et al., 2013). Persistent strong coupling corresponds to regions interpreted to have slipped in historical great earthquakes.

564 These time-dependent images of decadal variations in subduction zone coupling 565 reveal a diversity of behaviors from invariance to variability, challenge the notion of 566 universally persistent seismic asperities, and are consistent with the idea that continued 567 long-period geodetic observations may further expand the known range of earthquake 568 cycle behaviors. 


\section{Acknowledgements}

570 We gratefully acknowledge the Geospatial Information Authority of Japan (GSI) for

571 providing access to GEONET data. Information on seismicity comes from the Global

572 CMT Project. We thank Hannah Baranes, Michele Cooke, Louisa Hall, and Jon

573 Woodruff for helpful discussion, and two anonymous referees for thorough, thoughtful

574 reviews. Most figures were generated using the Generic Mapping Tools (Wessel et al.,

575 2013). The elastic block modeling code is available at

576 https://github.com/brendanjmeade/Blocks. Loveless was supported by a Jean Picker

577 Fellowship from Smith College.

\section{7. Figure captions}

579 Figure 1. a) Nominally interseismic velocity field for GEONET stations, April 1, 580 1996-December 31, 1999, expressed relative to the stable Eurasia reference frame of 581 Apel et al. (2006). b) Regions and localities of Japan referred to in the text. The labeled

582 darker gray regions comprise the island of Honshu. Position time series for stations 0144 583 and 0179 are shown in Figure 2.

584 Figure 2. East component of the observed position time series (gray dots) at stations 585 on the Pacific coast of Hokkaido (0144) and Tohoku (0179) with fits estimated using 586 Equation 1 (black line). Contributions to the fit from the piecewise linear (green) and

587 exponential (magenta) terms are each shown for three assumed exponential decay

588 durations: $2.5,5$, and 10 years as solid, dashed, and dash-dot lines, respectively. Red lines

589 show timing of the 2003 Tokachi-oki and 2011 Tohoku-oki earthquakes. Observed,

590 estimated, and linear plots have been detrended using the Epoch 1 (April 1, 1996- 
591 December 31, 1999) linear velocity estimate so that deviation from horizontal shows each

592 epoch's relative change in velocity (e.g., Figure 5). Station locations are shown in Figure 5931.

$594 \quad$ Figure 3. Covariance between estimated linear velocity (A term of Equation 1) and 595 exponential position change (E term of Equation 1) in the east direction during Epoch 3 596 (following the Tokachi-oki earthquake), evaluated for all stations across the suite of trial 597 exponential decay durations we test in our time series analysis. The color scale indicates 598 the normalized frequency distribution of exponential-linear combinations.

599 Figure 4. Estimated postseismic duration at each station in the epoch following the a) 6002003 Tokachi-oki and b) 2011 Tohoku-oki earthquakes, the Global CMT focal 601 mechanism for each of which is shown. We estimate the postseismic duration by 602 assuming that, for these post-earthquake epochs, a linear contribution to the fit to the 603 position time series (i.e., velocity) varies little compared to the velocity estimated for 604 Epoch 1 (1996.3-2000.0). We do so by choosing the variable that controls the decay 605 duration of an exponential function we use to model postseismic position change. Symbol 606 size indicates the total estimated displacement of the exponential function from the time 607 of the earthquake through the end of the noted epoch. The inset of each panel shows the 608 epoch's linear fit (velocity) vectors at a single station (location indicated by a black 609 triangle) given the tested range of postseismic decay durations. The Epoch 1 velocity

610 vector is shown as a solid black vector, and the chosen candidate vector for each 611 postseismic epoch is outlined in black. 
612 Figure 5. Changes in nominally interseismic velocities through time, relative to

613 Epoch 1 (1996-1999). Vector color indicates an increase (red) or decrease (blue) in

614 speed, length indicates the absolute value of speed change, and direction shows the

615 direction change. For example, the blue vectors in (a) indicate that stations in the Tokai

616 region moved up to $18 \mathrm{~mm} / \mathrm{yr}$ more slowly and more southeasterly during Epoch 2

617 (2000.0-2003.7) than during Epoch 1.

618 Figure 6. Spatiotemporal evolution of strong coupling on the Japanese subduction

619 zones. We use the nominally interseismic, minimally variable velocity fields to estimate

620 the spatial distribution of subduction zone coupling for each epoch. a-e) Colored contour

621 lines show regions where estimated slip deficit rate is $\geq 80 \%$ the relative tectonic block

622 motion rate (i.e., $\geq 80 \%$ coupled) during the listed epochs (current: thick; prior: thin).

623 These contours represent the mean coupling distribution from inversion of 5000

624 realizations of the velocity field, with synthetic noise proportional to station uncertainty.

625 Translucent shaded regions represent the standard deviation about the mean of strong

626 coupling estimated for the current epoch. For example, the thick black contours in (b)

627 show strongly coupled regions during Epoch 2, and the thin red contours show strong

628 coupling during Epoch 1 (repeated from panel a). The shaded gray regions surrounding

629 the black contour indicate the minimum and maximum areas of $\geq 80 \%$ coupling during

630 Epoch 2 from the uncertainty estimation, reflecting the mean coupling (black contour)

631 plus and minus, respectively, the standard deviation. Focal mechanisms show

632 earthquakes that occurred during each epoch, with the color of the compressive quadrant

633 indicating the timing. f) Duration of strong coupling. The color of each subduction zone 
634 element reflects the summed number of $\sim 3.75$-year epochs in which we estimate strong

635 coupling, using the mean values from our Monte Carlo simulations.

636 Figure 7. Spatiotemporal evolution of thrust-sense slip on the Japanese subduction

637 zones. As in Figure 6, we use the nominally interseismic, minimally variable velocity

638 fields to estimate the spatial distribution of subduction zone slip for each epoch and use a

639 Monte Carlo simulation to estimate uncertainties in slip contours. a-e) Hollow contours

640 show regions where estimated thrust-sense slip is $\geq 10 \%$ the magnitude of relative

641 tectonic block motion rate during the listed epochs (current: thick; prior: thin), and the

642 translucent shaded regions show the spatial range of estimated thrust-sense slip the

643 current epoch based on our uncertainty analysis, as described for Figure 6. Focal

644 mechanisms are as described for Figure 6. f) Duration of aseismic thrust-sense slip (of

645 rate $\geq 10 \%$ relative plate motion). The color of each subduction zone element reflects the

646 summed number of $\sim 3.75$-year epochs in which we estimate aseismic slip, using the

647 mean values from our Monte Carlo simulations as described in Figure 6.

648 Figure 8 . Estimated distribution of strong ( $\geq 80 \%)$ coupling for all epochs assuming a

649 temporally constant postseismic decay function. We show only the estimates for Epochs

$6503-5$; because the first earthquake after which we estimate a postseismic contribution to

651 the GPS time series occurs at the beginning of Epoch 3, the coupling estimated for

652 Epochs 1 and 2 appears similar regardless of assumed decay time. For visual clarity, we

653 do not show uncertainties on the estimated contours. Focal mechanisms are as described

654 in Figure 6. 
655 Figure S1. Same as Figure 6 but estimated without the constraint that slip deficit is 656 zero on triangular dislocation elements lining the subduction trenches.

657 Figure S2. Same as Figure 7 but estimated without the constraint that slip deficit is 658 zero on triangular dislocation elements lining the subduction trenches.

659 Figure S3. Same as Figure 8 but estimated without the constraint that slip deficit is 660 zero on triangular dislocation elements lining the subduction trenches.

661 Figure S4. Estimated distribution of thrust-sense slip ( $\geq 10 \%$ relative plate motion) for 662 all epochs assuming a temporally constant postseismic decay function. We show only the 663 estimates for Epochs 3-5; because the first earthquake after which we estimate a 664 postseismic contribution to the GPS time series occurs at the beginning of Epoch 3, the 665 coupling estimated for Epochs 1 and 2 appears similar regardless of assumed decay time.

666 For visual clarity, we do not show uncertainties on the estimated contours. Focal

667 mechanisms are as described in Figure 6.

668 Figure S5. Same as Figure S4 but estimated without the constraint that slip deficit is 669 zero on triangular dislocation elements lining the subduction trenches.

670 Figure S6. Nominally interseismic velocity fields for each epoch, expressed relative 671 to stable Eurasia, estimated using the minimally variable velocity field (MVVF) 672 approach.

673 Figure S7. Estimated coupling distribution from elastic block models, constrained 674 using the velocity fields shown in Figure S6. We define coupling as the ratio of the 675 magnitude of estimated slip deficit to the magnitude of relative plate motion projected 676 onto each triangular dislocation element. We take the sign of coupling to be the sign of 
677 the estimated slip deficit in the dip direction. In these models, we constrain the slip deficit

678 rate at the trench and at the downdip extent of the fault to be zero. Contours of these

679 coupling distributions appear in Figures 6 and 7.

680 Figure S8. Same as Figure S7 but with no constraint that the slip deficit near the 681 trench is zero, i.e., trench-unconstrained (TU) models. Contours of these coupling 682 distributions appear in Figures S1 and S2.

683 Table S1. Nominally interseismic velocities estimated from GEONET time series for 684 Epoch 1 using Equation 1. The columns are station name, longitude, latitude, east 685 velocity $(\mathrm{mm} / \mathrm{yr})$, east uncertainty $(\mathrm{mm} / \mathrm{yr})$, north velocity $(\mathrm{mm} / \mathrm{yr})$, north uncertainty $686(\mathrm{~mm} / \mathrm{yr})$.

687 Table S2. Nominally interseismic velocities estimated from GEONET time series for 688 Epoch 2 using Equation 1 for all trial values of $\tau_{2}$ (corresponding to decays of 6 months 689 to 5 years in 6 month increments; 6 to 10 years in 1 year increments; and 25, 50, and 100 690 years). The columns are station name, MVVF index (referred to below as $i$ ), MVVF 691 duration (years), longitude, latitude, and 23 sets of 4 columns containing east velocity $692(\mathrm{~mm} / \mathrm{yr})$, east mean residual position (between the observations and total fit to the data 693 during an epoch, $\mathrm{mm}$ ), north velocity ( $\mathrm{mm} / \mathrm{yr})$, north mean residual position $(\mathrm{mm})$, with 694 each set of 4 corresponding to a trial value of $\tau_{2}$. The MVVF east velocity, east

695 uncertainty, north velocity, and north uncertainty for a particular station are given in 696 columns $5+(4 i-3), 5+(4 i-2), 5+(4 i-1)$, and $5+(4 i-0)$, respectively.

697 Table S3. Same as Table S2 but for Epoch 3.

698 Table S4. Same as Table S2 but for Epoch 4. 
Table S6. Estimated volume rate changes at three volcanic centers during each of the

701 five epochs. Magma chamber volume change rates are estimated simultaneously with

702 microplate rotations and elastic earthquake cycle effects in our block modeling

703 methodology, using expressions relating volume change of a spherical body in an elastic

704 half space to radial surface velocity (Mogi, 1958). In the columns, we list the volcanic

705 center name, longitude, latitude, depth $(\mathrm{km})$, and estimated volume change rates with

706 uncertainties for each epoch. Results for each epoch occupy 4 columns: 1) volume

707 change rate (DV) for the trench-creeping (TC) models, 2) uncertainty in volume change

708 rate (DVSig) for the TC models, and 3) DV and 4) DVSig for the trench-unconstrained

709 (TU) models.

\section{References}

Apel, E.V., Burgmann, R., Steblov, G., Vasilenko, N., King, R., Prytkov, A., 2006. Independent active microplate tectonics of northeast Asia from GPS velocities and block modeling. Geophys. Res. Lett. 33, L11303, 10.1029/2006GL026077.

Bird, P., 2003. An updated digital model of plate boundaries. Geochem., Geophys., Geosys. 4, 1027, 10.1029/2001GC000252.

Diao, F., Xiong, X., Wang, R., Zheng, Y., Walter, T.R., Weng, H., Li, J., 2013. Overlapping post-seismic deformation processes: afterslip and viscoelastic relaxation following the $2011 \mathrm{Mw} 9.0$ Tohoku (Japan) earthquake. Geophys. J. Int. 196, 218 229, 10.1093/gji/ggt376.

Dragert, H., Wang, K., James, T.S., 2001. A silent slip event on the deeper Cascadia subduction interface. Science 292, 1525-1528, 10.1126/science.1060152.

Ergintav, S., McClusky, S., Hearn, E., Reilinger, R., Cakmak, R., Herring, T., Ozener, H., Lenk, O., Tari, E., 2009. Seven years of postseismic deformation following the 1999, $\mathrm{M}=7.4$ and $\mathrm{M}=7.2$, Izmit-Düzce, Turkey earthquake sequence. J. Geophys. Res. 114, 10.1029/2008JB006021.

Evans, E.L., Meade, B.J., 2012. Geodetic imaging of coseismic slip and postseismic afterslip: Sparsity promoting methods applied to the great Tohoku earthquake. Geophys. Res. Lett. 39, L11314, 10.1029/2012g1051990. 
Furumura, T., Imai, K., Maeda, T., 2011. A revised tsunami source model for the 1707 Hoei earthquake and simulation of tsunami inundation of Ryujin Lake, Kyushu,

Furuse, N., Kono, Y., 2003. Slab residual gravity anomaly: gravity reduction due to subducting plates beneath the Japanese Islands. J. Geodyn. 36, 497-514, 10.1016/S0264-3707(03)00062-0.

Gagnon, K., Chadwell, C.D., Norabuena, E., 2005. Measuring the onset of locking in the Peru-Chile trench with GPS and acoustic measurements. Nature 434, 205-208, 10.1038 /nature 03412 .

Hashimoto, C., Noda, A., Sagiya, T., Matsu'ura, M., 2009. Interplate seismogenic zones along the Kuril-Japan trench inferred from GPS data inversion. Nature Geoscience 2, 141-144, 10.1038/ngeo421.

Hashimoto, M., Jackson, D.D., 1993. Plate tectonics and crustal deformation around the Japanese islands. J. Geophys. Res. 98, 16149-16166, 10.1029/93JB00444.

Hashimoto, M., Miyazaki, S., Jackson, D.D., 2000. A block-fault model for deformation of the Japanese Islands derived from continuous GPS observation. EP\&S 52, 1095$1100,10.1186 /$ BF03352337.

Hearn, E.H., McClusky, S., Ergintav, S., Reilinger, R.E., 2009. Izmit earthquake postseismic deformation and dynamics of the North Anatolian Fault Zone. J. Geophys. Res. 114, B08405, 10.1029/2008JB006026.

Heki, K., Mitsui, Y., 2013. Accelerated pacific plate subduction following interplate thrust earthquakes at the Japan trench. E\&PSL 363, 44-49, 10.1016/j.epsl.2012.12.031.

Heki, K., Miyazaki, S., Tsuji, H., 1997. Silent fault slip following an interplate thrust earthquake at the Japan Trench. Nature 386, 595-597, 10.1038/386595a0.

Hirose, F., Nakajima, J., Hasegawa, A., 2008. Three-dimensional seismic velocity structure and configuration of the Philippine Sea slab in southwestern Japan estimated by double-difference tomography. J. Geophys. Res. 113, B09315, 10.1029/2007JB005274.

Hirose, H., Hirahara, K., Kimata, F., Fuiji, N., Miyazaki, S.i., 1999. A slow thrust slip even following the two 1996 Hyuganada earthquakes beneath the Bungo Channel, southwest Japan. Geophys. Res. Lett. 26, 3237-3240, 10.1029/1999GL010999.

Hyodo, M., Hori, T., Ando, K., Baba, T., 2014. The possibility of deeper or shallower extent of the source area of Nankai Trough earthquakes based on the 1707 Hoei tsunami heights along the Pacific and Seto Inland Sea coasts, southwest Japan. Earth, Planets and Space 66, 1-14, 10.1186/1880-5981-66-123.

Ide, S., Baltay, A., Beroza, G.C., 2011. Shallow Dynamic Overshoot and Energetic Deep Rupture in the $2011 \mathrm{Mw} 9.0$ Tohoku-Oki Earthquake. Science, $10.1126 /$ science. 1207020.

Ikuta, R., Satomura, M., Fujita, A., Shimada, S., Ando, M., 2012. A small persistent locked area associated with the $2011 \mathrm{Mw} 9.0$ Tohoku-Oki earthquake, deduced from GPS data. J. Geophys. Res. 117, B11408, 10.1029/2012JB009335.

Kodaira, S., Hori, T., Ito, A., Miura, S., Fujie, G., Park, J.-O., Baba, T., Sakaguchi, H., Kaneda, Y., 2006. A cause of rupture segmentation and synchronization in the Nankai trough revealed by seismic imaging and numerical simulation. J. Geophys. Res. 111, B09301, 10.1029/2005JB004030. 
Konca, A.O., Avouac, J.-P., Sladen, A., Meltzner, A.J., Sieh, K., Fang, P., Li, Z., Galetzka, J., Genrich, J., Chlieh, M., Natawidjaja, D.H., Bock, Y., Fielding, E.J., Ji, C., Helmberger, D.V., 2008. Partial rupture of a locked patch of the Sumatra megathrust during the 2007 earthquake sequence. Nature 456, 631-635, 10.1038/nature07572.

Li, S., Moreno, M., Bedford, J., Rosenau, M., Oncken, O., 2015. Revisiting visco-elastic effects on interseismic deformation and locking degree: a case study of the Peru North Chile subduction zone. J. Geophys. Res. 120, 4522-4538, 10.1002/2015JB011903.

Liu, Z., Owen, S., Dong, D., Lundgren, P., Webb, F., Hetland, E., Simons, M., 2010. Estimation of interplate coupling in the Nankai trough, Japan using GPS data from 1996 to 2006. Geophys. J. Int. 181, 1313-1328, 10.1111/j.1365-246X.2010.04600.x.

Loveless, J.P., Meade, B.J., 2010. Geodetic imaging of plate motions, slip rates, and partitioning of deformation in Japan. J. Geophys. Res. 115, B02410, 10.1029/2008JB006248.

Loveless, J.P., Meade, B.J., 2011. Spatial correlation of interseismic coupling and coseismic rupture extent of the $2011 \mathrm{M}_{\mathrm{W}}=9.0$ Tohoku-oki earthquake. Geophys. Res. Lett. 38, L17306, 10.1029/2011GL048561.

Loveless, J.P., Meade, B.J., 2015. Kinematic Barrier Constraints on the Magnitudes of Additional Great Earthquakes Off the East Coast of Japan. Seismological Research Letters 86, 202-209, 10.1785/0220140083.

Mavrommatis, A.P., Segall, P., Johnson, K.M., 2014. A decadal-scale deformation transient prior to the $2011 \mathrm{Mw} 9.0$ Tohoku-oki earthquake. Geophys. Res. Lett. 41, 4486-4494, 10.1002/2014GL060139.

McCaffrey, R., Long, M., Goldfinger, C., Zwick, P.C., Nabalek, J.L., Johnson, C.K., Smith, C., 2000. Rotation and plate locking at the southern Cascadia subduction zone. Geophys. Res. Lett. 27, 3117-3120, 10.1029/2000GL011768.

Meade, B.J., Loveless, J.P., 2009. Block modeling with connected fault network geometries and a linear elastic coupling estimator in spherical coordinates. Bull. Seis. Soc. Am. 99, 3124-3139, 10.1785/0120090088.

Miyazaki, S.i., Segall, P., McGuire, J.J., Kato, T., Hatanaka, Y., 2006. Spatial and temporal evolution of stress and slip rate during the 2000 Tokai slow earthquake. J. Geophys. Res. 111, B03409, 10.1029/2004JB003426.

Mogi, K., 1958. Relations between the eruptions of various volcanoes and the deformations of the ground surface around them. Bulletin of the Earthquake Research Institute of the University of Tokyo 36, 99-134.

Nakamura, M., 2004. Crustal deformation in the central and southern Ryukyu Arc estimated from GPS data. E\&PSL 217, 389-398, 10.1016/S0012-821X(03)00604-6.

Nakata, T., Imaizumi, T., 2002. Digital Active Fault Map of Japan. University of Tokyo Press, Tokyo.

Nanayama, F., Satake, K., Furukawa, R., Shimokawa, K., Atwater, B.F., Shigeno, K., Yamaki, S., 2003. Unusually large earthquakes inferred from tsunami deposits along the Kuril trench. Nature 424, 660-663, 10.1038/Nature01864.

Nishimura, S., Hashimoto, M., 2006. A model with rigid rotations and slip deficits for the GPS-derived velocity field in Southwest Japan. Tectonophys. 421, 187-207, 10.1016/j.tecto.2006.04.017. 
Nishimura, T., Hirasawa, T., Miyazaki, S., Sagiya, T., Tada, T., Miura, S., Tanaka, K., 2002 estimated from continuous GPS observations. Geophys. J. Int. 157, 901-916, 10.1111/j.1365-246X.2004.02159.x.

Nishimura, T., Sagiya, T., Stein, R.S., 2007. Crustal block kinematics and seismic potential of the northernmost Philippine Sea plate and Izu microplate, central Japan, inferred from GPS and leveling data. J. Geophys. Res. 112, B05414, 10.1029/2005JB004102.

Ochi, T., Kato, T., 2013. Depth extent of the long-term slow slip event in the Tokai district, central Japan: A new insight. J. Geophys. Res. 118, 4847--4860, 10.1002/jgrb.50355.

Ozawa, S., Miyazaki, S., Hatanaka, Y., Imakiire, T., Kaidzu, M., Murakami, M., 2003. Characteristic silent earthquakes in the eastern part of the Boso peninsula, Central Japan. Geophys. Res. Lett. 30, 1283, 10.1029/2002GL016665.

Ozawa, S., Nishimura, T., Munekane, H., Suito, H., Kobayashi, T., Tobita, M., Imakiire, T., 2012. Preceding, coseismic, and postseismic slips of the 2011 Tohoku earthquake, Japan. J. Geophys. Res. 117, B07404, 10.1029/2011JB009120.

Ozawa, S., Suito, H., Tobita, M., 2007. Occurrence of quasi-periodic slow-slip off the east coast of the Boso peninsula, Central Japan. Earth Planets Space 59, 1241-1245, 10.1186/BF03352072.

Ozawa, S., Yarai, H., Imakiire, T., Tobita, M., 2013. Spatial and temporal evolution of the long-term slow slip in the Bungo Channel, Japan. Earth, Planets, Space 65, 67-73, 10.5047/eps.2012.06.009.

Pollitz, F.F., Peltzer, G., Bürgmann, R., 2000. Mobility of continental mantle: Evidence from postseismic geodetic observations following the 1992 Landers earthquake. J. Geophys. Res. 105, 8035-8054, 10.1029/1999JB900380.

Protti, M., Gonzalez, V., Newman, A.V., Dixon, T.H., Schwartz, S.Y., Marshall, J.S., Feng, L., Walter, J.I., Malservisi, R., Owen, S.E., 2014. Nicoya earthquake rupture anticipated by geodetic measurement of the locked plate interface. Nature Geoscience 7, 117-121, 10.1038/ngeo2038.

Sagiya, T., Miyazaki, S., Tada, T., 2000. Continuous GPS array and present-day crustal deformation of Japan. PApGe 157, 2303-2322, 10.1007/PL00022507.

Sagiya, T., Thatcher, W., 1999. Coseismic slip resolution along a plate boundary megathrust: The Nankai Trough, southwest Japan. J. Geophys. Res. 104, 1111-1129, 10.1029/98JB02644.

Sun, T., Wang, K., Iinuma, T., Hino, R., He, J., Fujimoto, H., Kido, M., Osada, Y., Miura, S., Ohta, Y., Hu, Y., 2014. Prevalence of viscoelastic relaxation after the 2011 Tohoku-oki earthquake. Nature 514, 84-87, 10.1038/nature13778.

Tanioka, Y., Satake, K., 2001. Coseismic slip distribution of the 1946 Nankai earthquake and aseismic slips caused by the earthquake. Earth, Planets and Space 53, 235-241, 10.1186/BF03352380.

Toda, S., Stein, R.S., Kirby, S.H., Bozkurt, S.B., 2008. A slab fragment wedged under Tokyo and its tectonic and seismic implications. Nature Geoscience 1, 771-776, 10.1038/ngeo318. 
865 Wessel, P., Smith, W.H.F., Scharroo, R., Luis, J., Wobbe, F., 2013. Generic Mapping

866 Tools: Improved Version Released. Eos, Transactions American Geophysical Union 94, 867 409--410, 10.1002/2013EO450001.

868 Yamagiwa, S., Miyazaki, S.i., Hirahara, K., Fukahata, Y., 2015. Afterslip and

869 viscoelastic relaxation following the 2011 Tohoku-oki earthquake (Mw9.0) inferred from

870 inland GPS and seafloor GPS/Acoustic data. Geophys. Res. Lett. 42, 66--73,

871 10.1002/2014GL061735.

872 


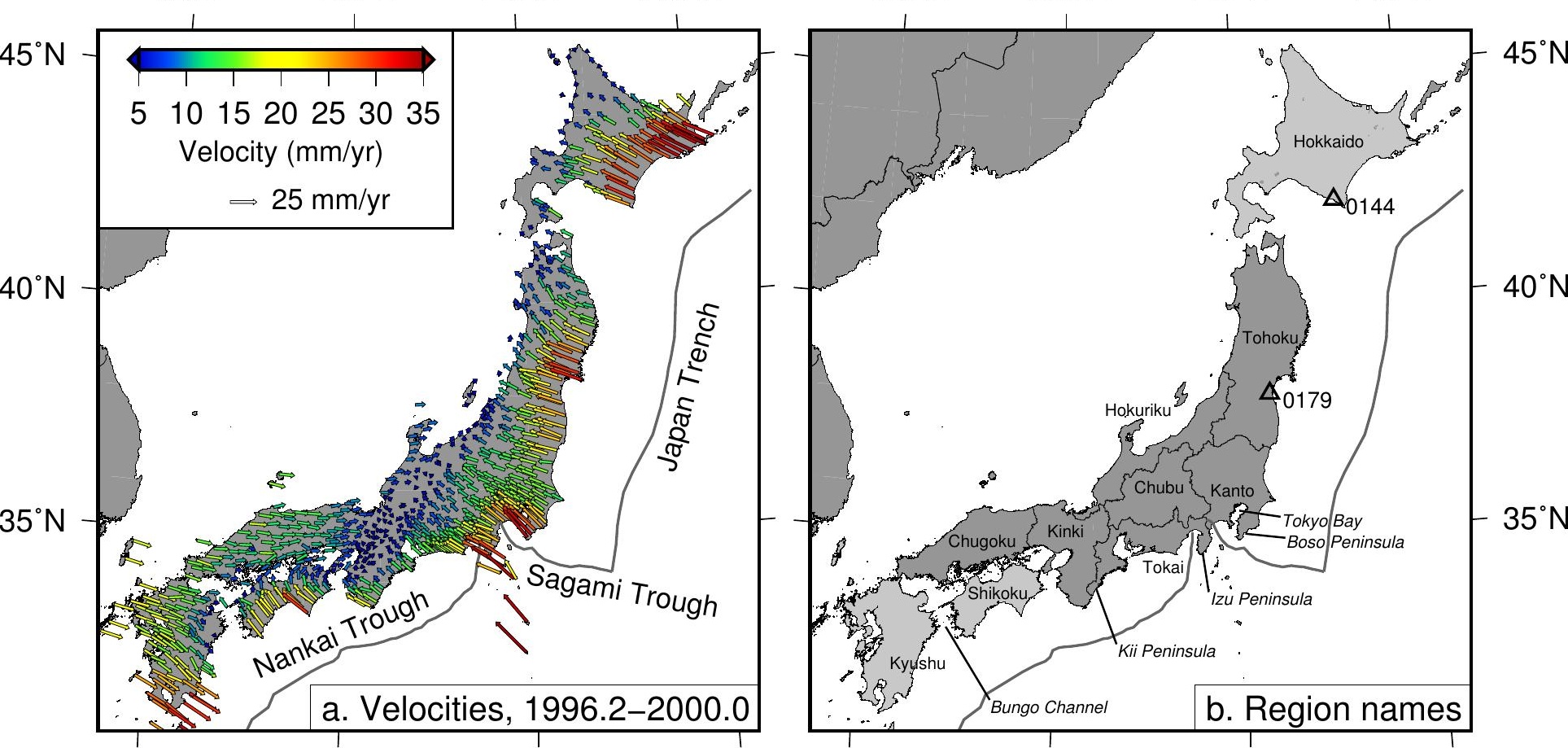




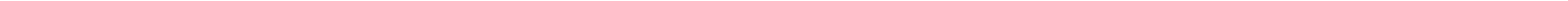




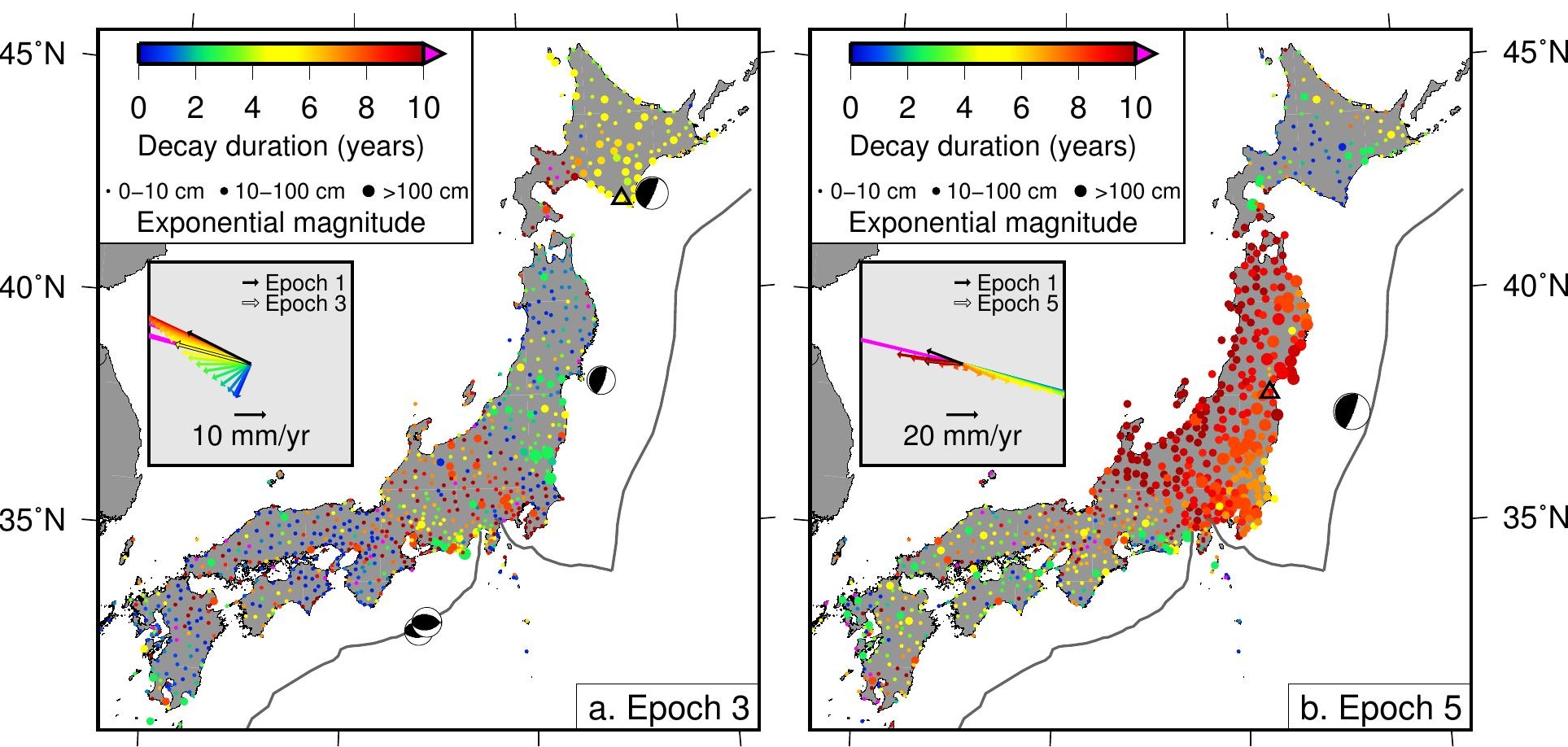




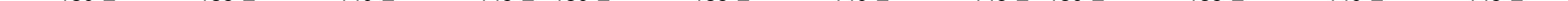




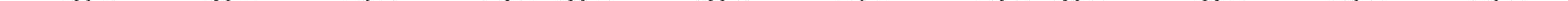




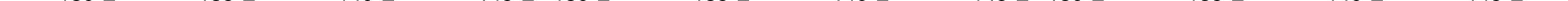




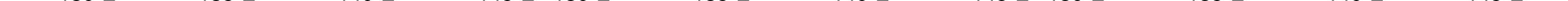



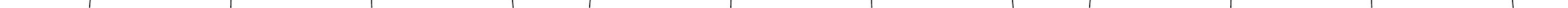


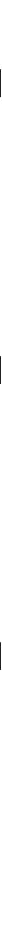



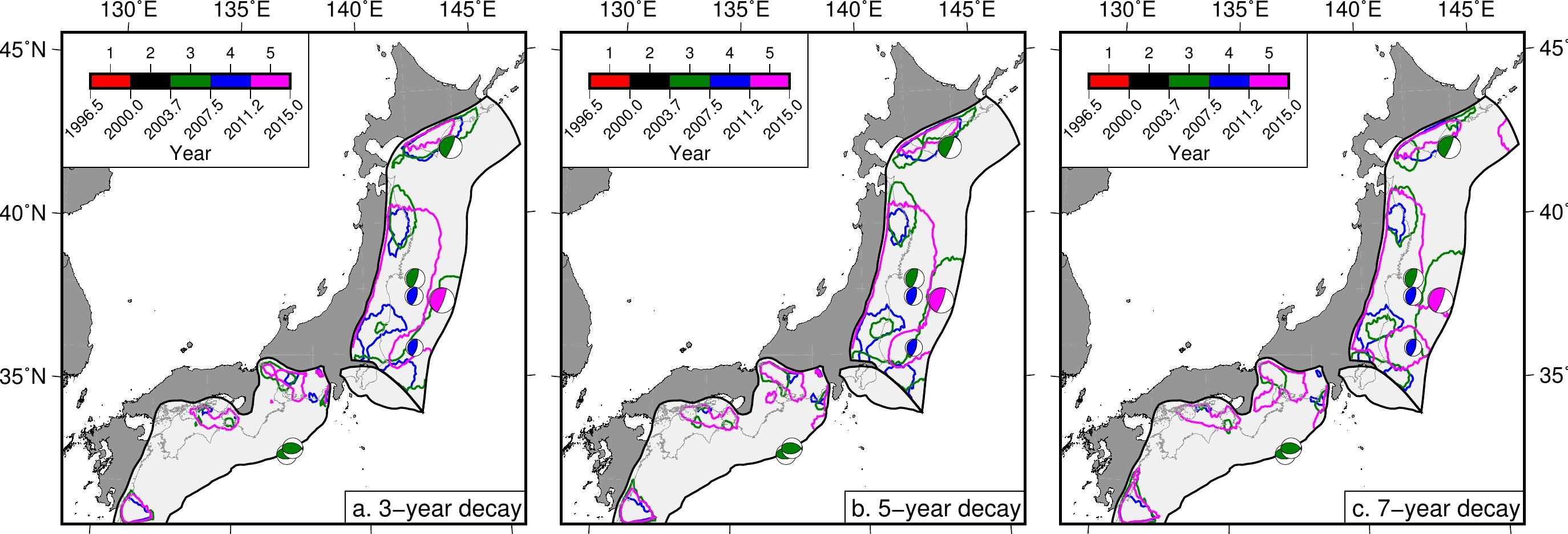


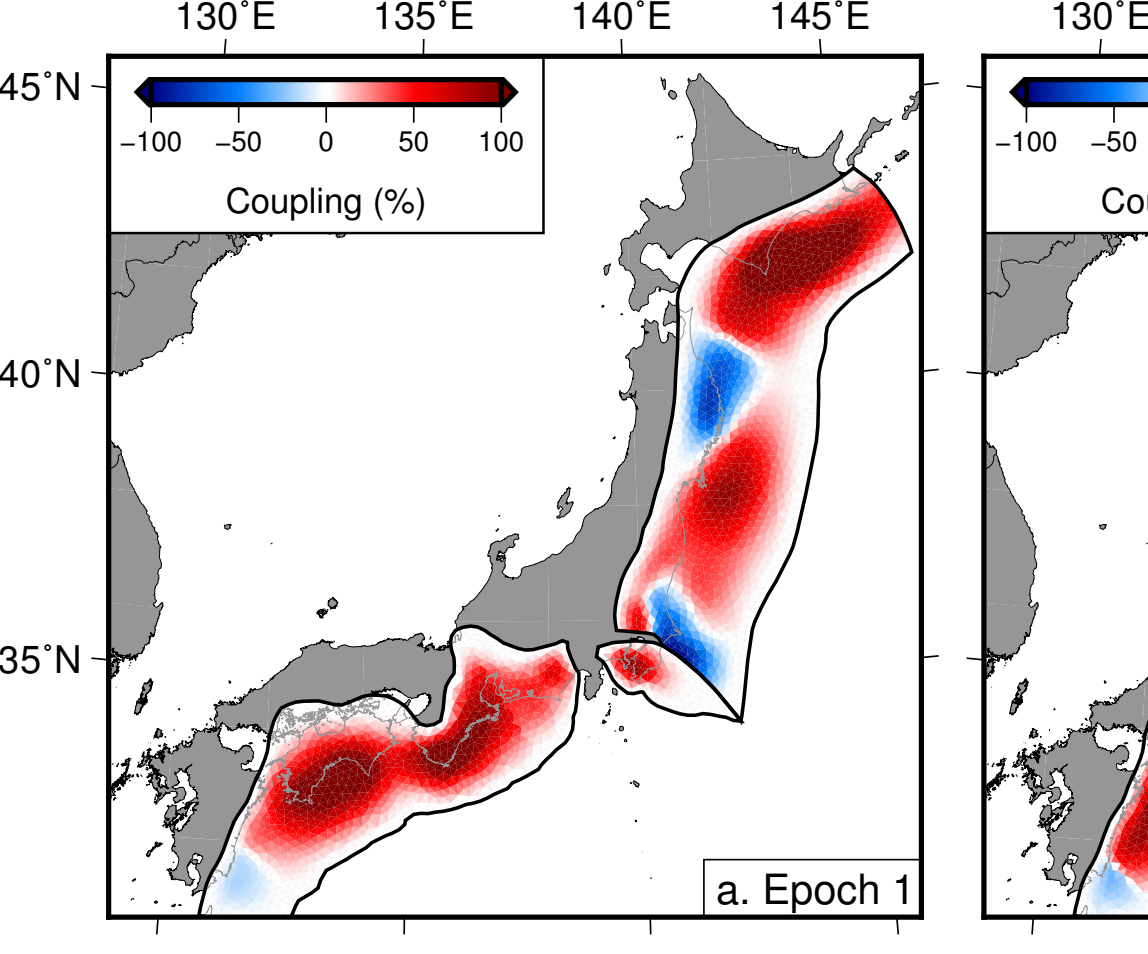

$130^{\circ} \mathrm{E} \quad 135^{\circ} \mathrm{E}$

$140^{\circ} \mathrm{E} \quad 145^{\circ} \mathrm{E}$

$130^{\circ} \mathrm{E} \quad 135^{\circ} \mathrm{E}$
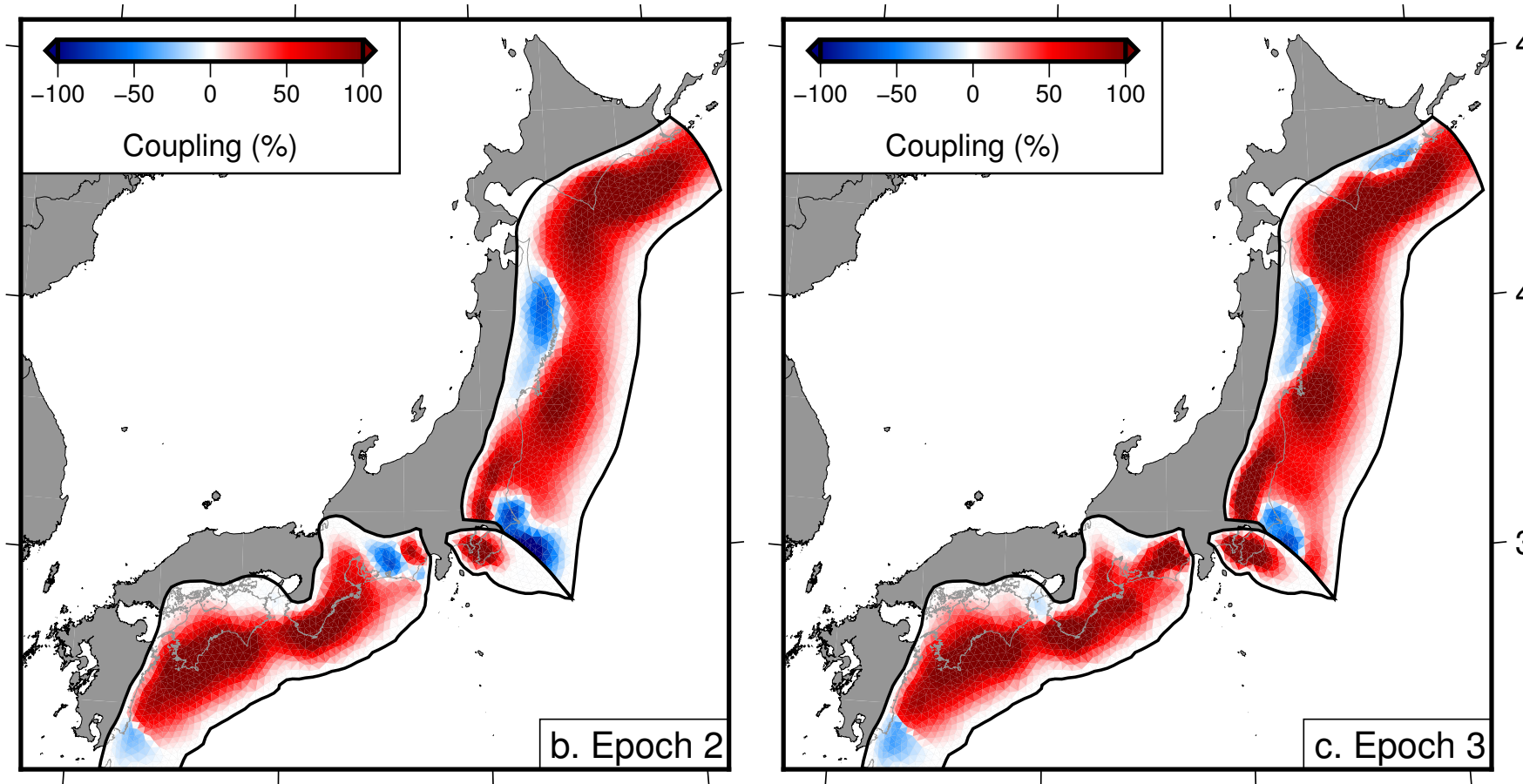

$-45^{\circ} \mathrm{N}$
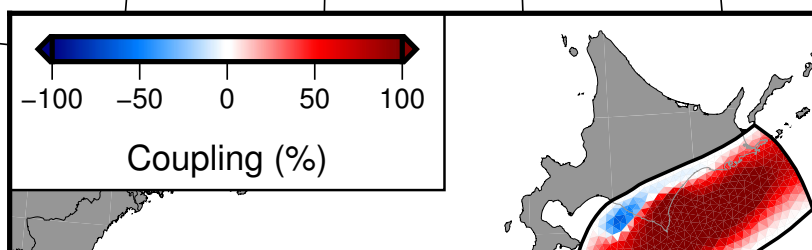

$40^{\circ} \mathrm{N}$
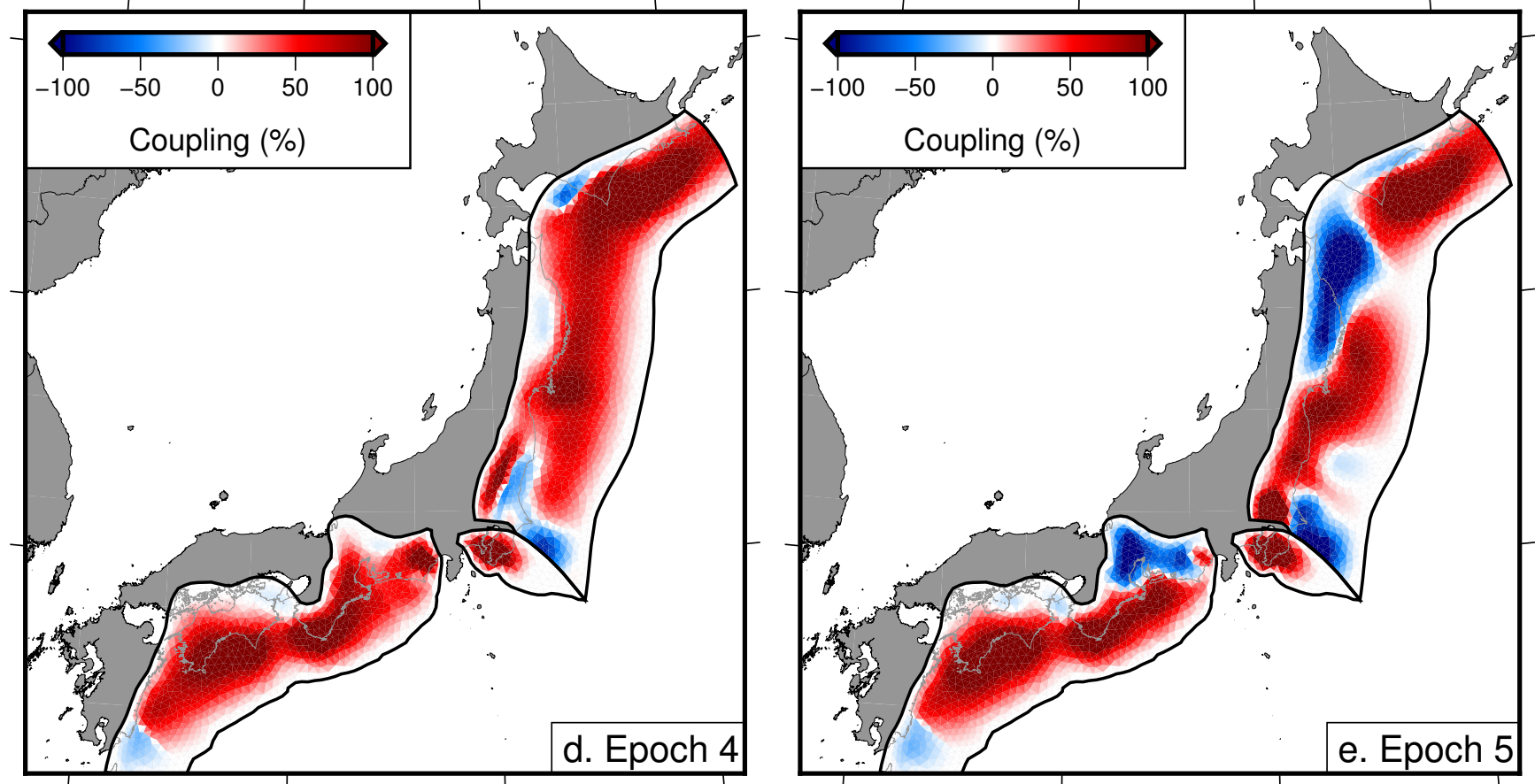

$-45^{\circ} \mathrm{N}$

$40^{\circ} \mathrm{N}$

$35^{\circ} \mathrm{N}$

$130^{\circ} \mathrm{E}$

$135^{\circ} \mathrm{E}$

$145^{\circ} \mathrm{E} \quad 130^{\circ} \mathrm{E}$

$135^{\circ} \mathrm{E}$

$140^{\circ} \mathrm{E}$

$145^{\circ} \mathrm{E}$ 


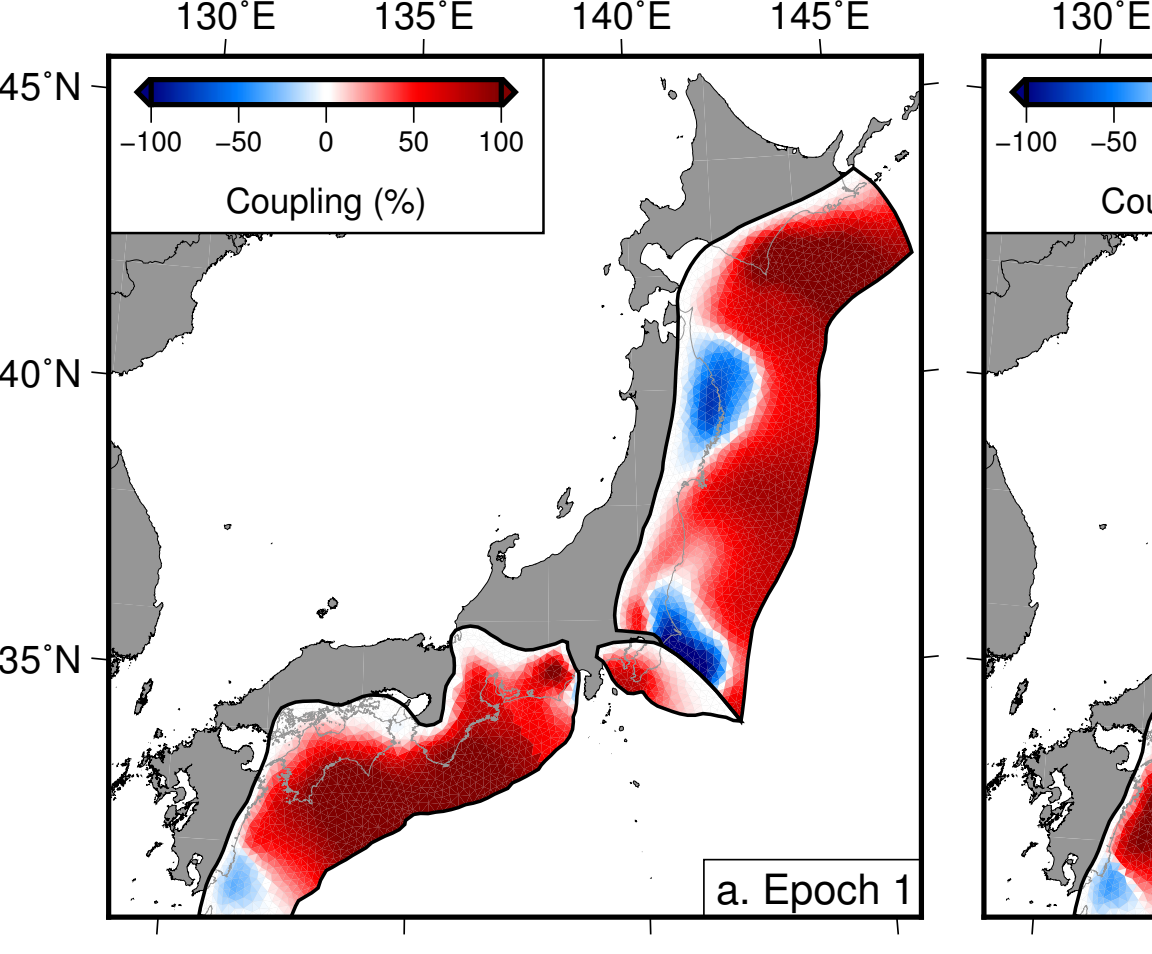

$130^{\circ} \mathrm{E} \quad 135^{\circ} \mathrm{E}$

$140^{\circ} \mathrm{E} \quad 145^{\circ} \mathrm{E}$

$130^{\circ} \mathrm{E} \quad 135^{\circ} \mathrm{E}$
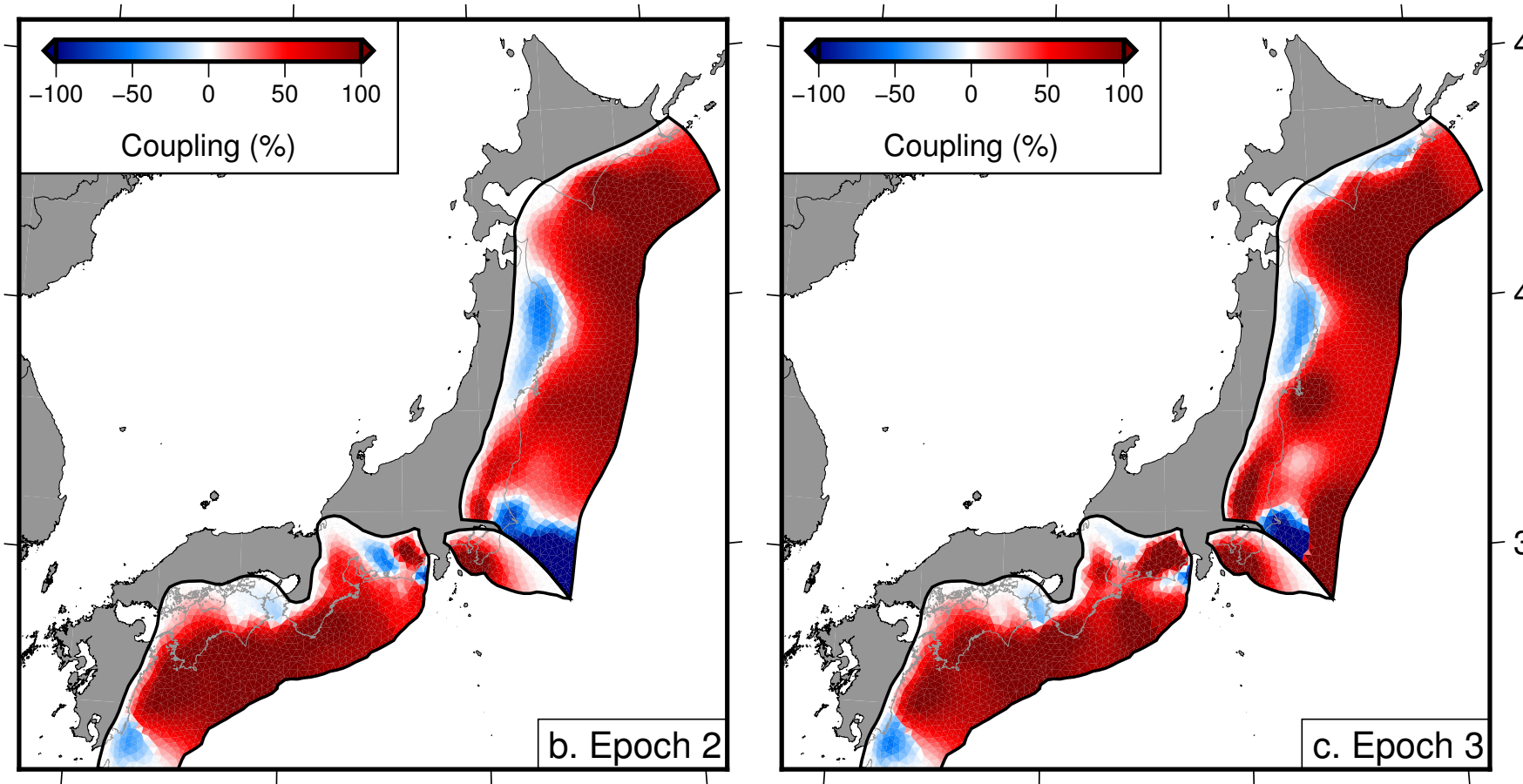

$-45^{\circ} \mathrm{N}$

$45^{\circ} \mathrm{N}$
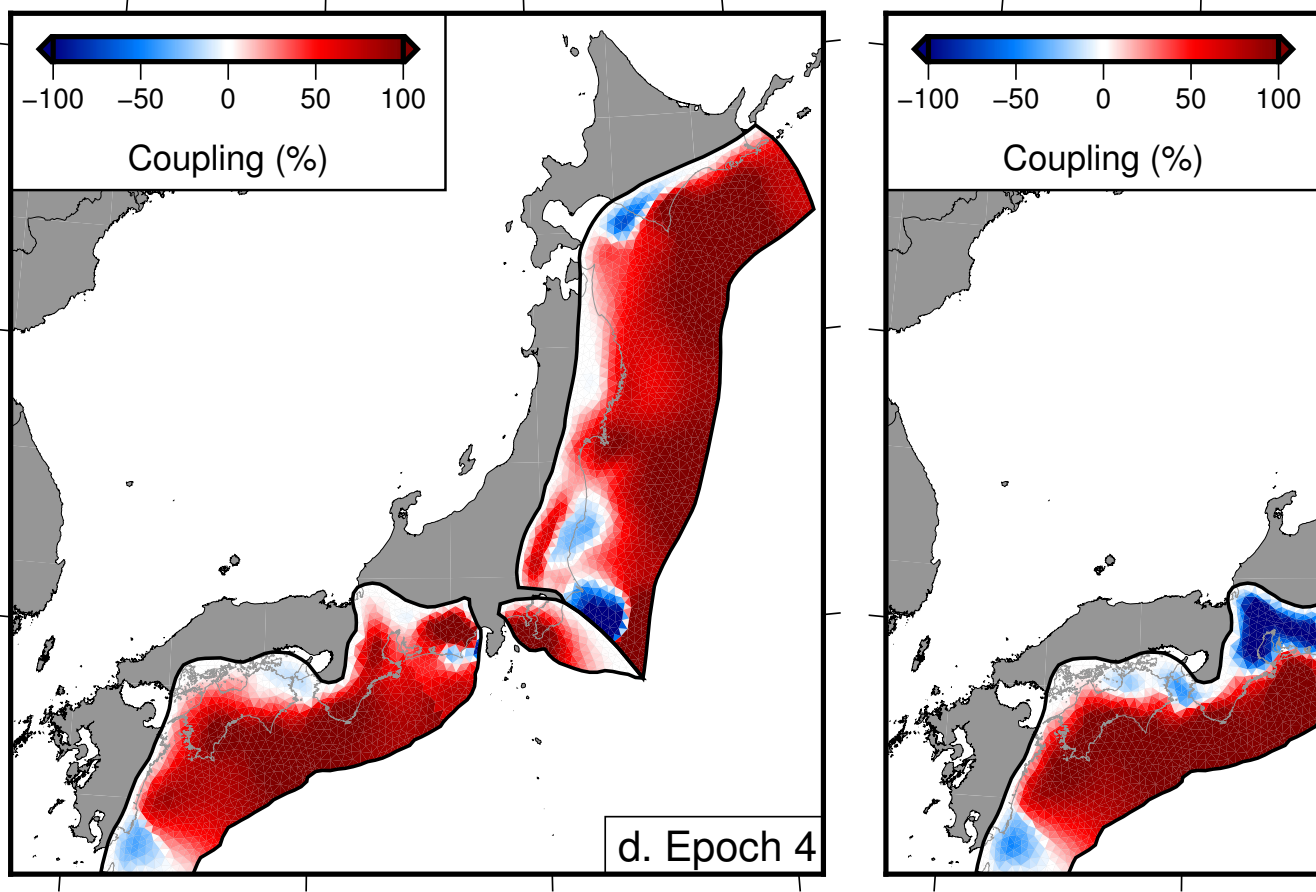

Coupling (\%)

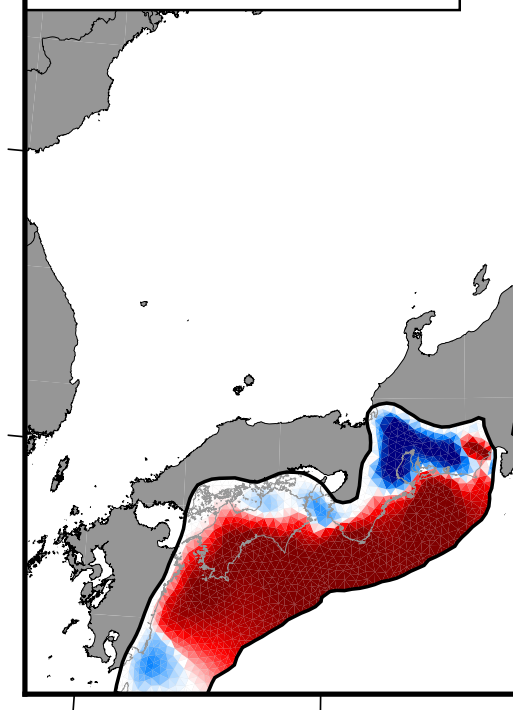

$135^{\circ} \mathrm{E}$

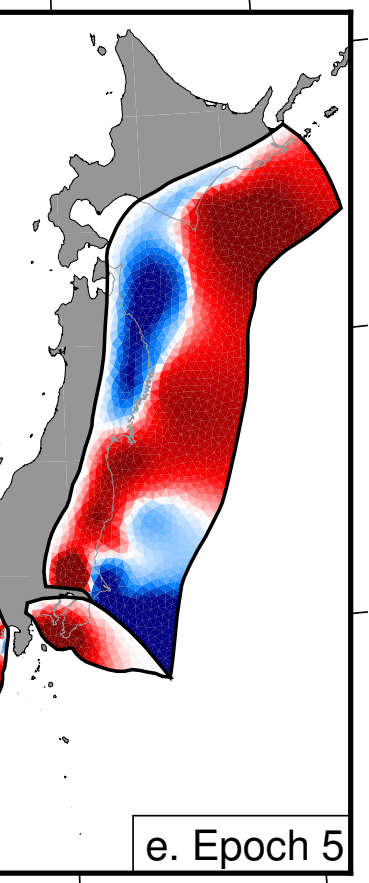

$145^{\circ} \mathrm{E}$ 